\title{
GDE2 is essential for neuronal survival in the postnatal mammalian spinal cord
}

\author{
Clinton Cave', Sungjin Park ${ }^{1,4}$, Marianeli Rodriguez ${ }^{1,5}$, Mai Nakamura' ${ }^{1}$, Ahmet Hoke², Mikhail Pletnikov ${ }^{3}$ \\ and Shanthini Sockanathan ${ }^{1 *}$
}

\begin{abstract}
Background: Glycerophosphodiester phosphodiesterase 2 (GDE2) is a six-transmembrane protein that cleaves glycosylphosphatidylinositol (GPI) anchors to regulate GPI-anchored protein activity at the cell surface. In the developing spinal cord, GDE2 utilizes its enzymatic function to regulate the production of specific classes of motor neurons and interneurons; however, GDE2's roles beyond embryonic neurogenesis have yet to be defined.

Method: Using a panel of histological, immunohistochemical, electrophysiological, behavioral, and biochemistry techniques, we characterized the postnatal Gde2 ${ }^{-1-}$ mouse for evidence of degenerative neuropathology. A conditional deletion of Gde2 was used to study the temporal requirements for GDE2 in neuronal survival. Biochemical approaches identified deficits in the processing of GPI-anchored GDE2 substrates in the SOD1 ${ }^{\mathrm{G} 93 \mathrm{~A}}$ mouse model of familial Amyotrophic Lateral Sclerosis that shows robust motor neuron degeneration.
\end{abstract}

Results: Here we show that GDE2 expression continues postnatally, and adult mice lacking GDE2 exhibit a slow, progressive neuronal degeneration with pathologies similar to human neurodegenerative disease. Early phenotypes include vacuolization, microgliosis, cytoskeletal accumulation, and lipofuscin deposition followed by astrogliosis and cell death. Remaining motor neurons exhibit peripheral motor unit restructuring causing behavioral motor deficits. Genetic ablation of GDE2 after embryonic neurogenesis is complete still elicits degenerative pathology, signifying that GDE2's requirement for neuronal survival is distinct from its involvement in neuronal differentiation. Unbiased screens identify impaired processing of Glypican 4 and 6 in Gde2 null animals, and Glypican release is markedly reduced in $\mathrm{SOD} 1^{\mathrm{G} 93 \mathrm{~A}}$ mice.

Conclusions: This study identifies a novel function for GDE2 in neuronal survival and implicates deregulated GPIanchored protein activity in pathways mediating neurodegeneration. These findings provide new molecular insight for neuropathologies found in multiple disease settings, and raise the possibility of GDE2 hypofunctionality as a component of neurodegenerative disease.

Keywords: GDE2, Motor neuron, Neurodegeneration, GPI-Anchor

\section{Background}

Throughout life, neurons must contend with a multitude of stresses both intrinsic and extrinsic. Supplied with only a finite number from birth, and excluding a few notable neurogenic niches $[1,2]$, the adult nervous system has no method for the bulk replacement of a neuronal population. As such, the nervous system must employ distinct mechanisms to actively ensure neuronal health and

\footnotetext{
* Correspondence: ssockan1@jhmi.edu

${ }^{1}$ The Solomon H. Snyder Department of Neuroscience, Johns Hopkins University School of Medicine, 725 N Wolfe Street, PCTB 1004, Baltimore, MD 21205, USA

Full list of author information is available at the end of the article
}

survival. What these mechanisms are and how they integrate with cellular pathways are not well understood. Moreover, identifying proteins responsible for neuronal survival is crucial to understand the multifactorial pathogenesis of human neurodegenerative disease.

The six-transmembrane glycerophosphodiester phosphodiesterases (GDEs) are a small family of three proteins that are related to a larger group of one-pass, two-pass and secreted proteins through common possession of an enzymatic domain homologous to bacterial glycerophosphodiester phosphodiesterase (GDPD) $[3,4]$. Six-transmembrane GDEs consist of GDE2, GDE3 
and GDE6, and their enzymatic GDPD domains face the extracellular space $[3,5]$. During embryogenesis, GDE2, also known as GDPD5, is expressed in postmitotic neurons in the spinal cord and the brain. Functional studies in the mouse and chick demonstrate that GDE2 is necessary and sufficient for motor neuron generation. In the developing chick spinal cord, overexpression of GDE2 in motor neuron progenitors drives their premature differentiation into postmitotic motor neurons, while ablating GDE2 by RNA interference profoundly reduces motor neuron differentiation $[6,7]$. GDE2 plays analogous roles in mammalian neurodevelopment. Gde2 knock out (KO) mice fail to generate specific subsets of late born alpha motor neurons as well as distinct populations of spinal interneurons $[8,9]$. In the brain, GDE2 loss leads to a decrease in deep layer neurons but an expansion of upper layer neurons [10]. Importantly, point mutations to critical residues within the enzymatic GDPD domain abolish GDE2's ability to promote differentiation, demonstrating the central role of extracellular enzymatic activity to GDE2 function [6].

Glycosylphosphatidylinositol (GPI)-anchorage is a common post-translational modification employed to adhere proteins to the extracellular leaflet of the plasma membrane via covalent attachment of a lipid moiety to the protein's C-terminus [11]. Approximately $10-20 \%$ of all cell surface protein is GPI-anchored while over 150 unique mammalian proteins have known GPI-anchorages [12]. Activities of soluble versus membrane-tethered GPI-anchored proteins differ, implying a critical role for pathways that release GPI-anchored proteins from the cell membrane. We have shown that GDE2 possesses the unique capacity to cleave within the GPIanchor of proteins tethered to the cell surface. During motor neuron differentiation, GDE2 functionally inactivates RECK (REversion-inducing Cysteine-rich protein with Kazal motifs) by cleaving its GPI-anchor, releasing it from the cell surface of motor neurons. This leads to a non-cell autonomous decrease in Notch signaling in neighboring progenitors, promoting cell-cycle exit and differentiation. Similarly, GDE2 mediated cleavage of Glypican 6 at the cell surface has recently been reported to promote the differentiation of neuroblastoma cells [13]. GPI-anchor cleaving activities were also detected in GDE3 and GDE6, providing evidence that the sixtransmembrane GDEs are the first known GPI-anchor cleaving enzymes in mammals that function at the cell surface [9]. Interestingly, a number of GPI-anchored proteins have been implicated in neurodegenerative disease. For example, conversion of GPI-anchored cellular prion protein into cytotoxic aggregates is a main focus in Creutzfeld-Jacob disease [14]. Expression of GPI-anchored CD59 has been shown to be neuroprotective in neurons and decreased expression has been reported in the brains of patients with Alzheimer's Disease (AD) [15], and aberrant Glypican processing has been detected in the context of $\mathrm{AD}$ and Niemann-Pick Disease [16, 17]. In Amyotrophic Lateral Sclerosis (ALS), expression of GPIanchored Ephrin A5 and uPAR are both significantly altered $[18,19]$. These observations underscore the importance of GPI-anchor regulation in disease, and open an avenue for GDE2 dysfunction to mediate aspects of neurodegeneration.

Here, we find that aged Gde2 KO mice develop a protracted, progressive neurodegeneration afflicting spinal motor neurons that resembles pathologies frequently observed across human neurodegenerative settings [20, 21]. Timed ablation of GDE2 after motor neuron differentiation is complete elicits neurodegeneration in adult animals, indicating that GDE2 function in neuronal survival is distinct from its role in embryonic neurogenesis. In addition, we observe the reduced release of Glypican proteins that are known substrates of GDE2 in $S O D 1^{\mathrm{G} 93 \mathrm{~A}}$ animals, which exhibit profound motor neuron degeneration. This study identifies GDE2 as an important regulator of neuronal survival in the adult nervous system, and invokes the possibility that deregulated GPI-anchored substrate activities are components of motor neuron degenerative pathways.

\section{Methods}

\section{Animal husbandry}

Mice were maintained and used in accordance with approved Johns Hopkins University IACUC protocols. $G d e 2^{+/-}$and Gde2 ${ }^{\text {lox/+ }}$ mice with mixed backgrounds (129/SV x C57BL/6J) were out-crossed to C57BL/6 J (Jackson Laboratories 000664) for four generations. Gde $2^{\mathrm{lox} /+} ; R O S A: \mathrm{Cre}^{\mathrm{ER}}$ mice were maintained on a C57BL/ 6J background and crossed with $G d e 2^{-/-}$for conditional ablation of Gde2. B6SJL-Tg(SOD1*G93A)1Gur/J mice were obtained from Jackson Laboratory (Stock\# 002726), and maintained as a hemizygous line on a C57BL/6J background. Animals for 6 month motor neuron counts were pooled from 6 to 7 month old animals. Genotyping primers, competitive PCR analysis, and 4-OHT administration are as previously described [8], and B6SJL$\mathrm{Tg}(\mathrm{SOD} 1 * \mathrm{G} 93 \mathrm{~A}) 1 \mathrm{Gur} / \mathrm{J}$ mice were genotyped as specified by Jackson Laboratory.

\section{Tissue preparation}

Animals were anesthetized with Avertin solution (1.3\% 2,2,2-Tribromorethanol (Fluka 90710) and 0.7\% 2methyl-2-butanol (Sigma 240486) in Phosphate Buffered Saline (PBS)) delivered via intraperitoneal injection at $0.02 \mathrm{ml} / \mathrm{g}$ body weight. After confirming the absence of a pain reflex, animals were transcardially perfused with $0.1 \mathrm{M}$ Phosphate Buffer (PB) followed by $4 \%$ paraformaldehyde (PFA) in $0.1 \mathrm{M} \mathrm{PB}$. Regions of interest 
were dissected and processed into cyromolds or paraffin blocks. Cryosections: Tissue samples were post-fixed in $4 \%$ PFA for $1 \mathrm{~h}$ at $4{ }^{\circ} \mathrm{C}$, rinsed in PBS, and incubated in $30 \%$ sucrose for 12-24 h. Samples were embedded in O.C.T Compound (Tissue-Tek 62550-12) and flash frozen in a dry ice ethanol bath. Cryomolds were stored at $-80{ }^{\circ} \mathrm{C}$ and sectioned on an UltraPro 5000 Cryostat (Vibratome). Paraffin Sections: Tissue samples were post-fixed in $4 \%$ PFA for $12-15 \mathrm{~h}$ at $4{ }^{\circ} \mathrm{C}$, rinsed in PBS, and incubated in Decalcifying Solution-Lite (Sigma D0818-1L) for $7 \mathrm{~h}$ at room temperature. Samples were then dehydrated in a graded ethanol series and cleared in Xylenes (Fisher Scientific X3P-1GAL). Samples were then infiltrated in Blue Ribbon Paraffin wax (Leica Microsystems 3801360) for $12-15 \mathrm{~h}$ and embedded. Sections were cut with a Rotary Microtome (Leica RM2235). For staining, slides were deparaffinized in Xylenes (Fisher Scientific X3P-1GAL), and rehydrated in an ethanol series. After staining, fluorescent slides were dehydrated in ethanol and coverslipped with Vectashield mounting medium (Vector Laboratories H1000); pathology slides were cleared with Xylenes, and coverslipped with Permount (Fisher Scientific SP15-500).

\section{Pathology stains}

Hematoxylin and Eosin: Sections were incubated in Harris Hematoxylin (VWR 95057-858) for $8 \mathrm{~min}$, differentiated in $1 \%$ acid alcohol for $4 \mathrm{~s}$, and incubated in Bluing Reagent Solution (VWR 95057-852) for 2 min. Sections were then counterstained with Eosinphloxine solution (VWR 95057-846). For quantification, a vacuolated neuron was defined as having 2 or more clear somal abscesses greater than $2 \mu \mathrm{m}$ in diameter. A minimum of 200 neurons were analyzed per animal. Sudan Black B: Sections were incubated in 1\% Sudan Black B (Sigma 199664-25G) in 70\% ethanol for 2 min. Kohler illuminated brightfield images were acquired on an Axioskop 2 (Zeiss) with a Retiga 2000R CCD camera (QImaging). Brightness and contrast were adjusted equally between experimental conditions. Post-hoc color balance was adjusted to achieve uniform white balance on all images.

\section{Fluorescent in-situ hybridization}

In-situ hybridizations were performed with modifications from Schaeren-Wiemers and Gerfin-Moser, 1993 [22]. Briefly, endogenous peroxidase activity was blocked with $0.3 \%$ hydrogen peroxide $+0.1 \%$ sodium azide. Sections were acetylated in $0.5 \%$ acetic anhydride and permeabilized with $0.1 \%$ Triton X-100 (Sigma T8787). Slides were hybridized with digoxigenin-labeled probe overnight at $65{ }^{\circ} \mathrm{C}$ in an RNAse free chamber. $680 \mathrm{bp}$ sense and antisense probes were generated from the 3' UTR of mouse Gde2. After hybridization, sections were washed with $50 \%$ formamide/sodium citrate buffers at
$65{ }^{\circ} \mathrm{C}$. Sections were treated with blocking buffer (Roche 11096176001) and incubated with sheep anti-digoxigeninPOD, 1:250 (Roche 11207733910) overnight at $4{ }^{\circ} \mathrm{C}$. Fluorescent signal was developed with the Tyramide Signal Amplification Kit (PerkinElmer NEL741001KT) according to the manufacturer's instructions.

\section{Immunohistochemistry}

Sections were washed in Phosphate Buffered Saline + 0.3\% Triton X-100 (PBST) and microwave boiled in $10 \mathrm{mM}$ sodium citrate, $\mathrm{pH} 6.0$ for $10 \mathrm{~min}$ for antigen retrieval. Slides were blocked with $5 \%$ bovine serum albumin and incubated with primary antibodies overnight at $4{ }^{\circ} \mathrm{C}$. Primary antibodies were visualized with fluorescently conjugated secondary antibodies (Jackson Immunoresearch). Whole mount muscle staining was performed without antigen retrieval. Dissected muscle was incubated in primary antibody + Alexa 488 conjugated $\alpha$-Bungarotoxin (Invitrogen B13422) for $24 \mathrm{~h}$ at room temperature and incubated in secondary antibody for $48 \mathrm{~h}$ at room temperature while rotating. Confocal images were taken on a Zeiss LSM 700 with identical acquisition parameters between experimental groups. Any image contrast and brightness adjustments were made equally between experimental groups. GFAP area fraction was calculated in ImageJ by thresholding regions of interest (ROI) above background and dividing the area of the $\mathrm{GFAP}^{+}$processes by the total ROI area $\left(150 \mathrm{\mu m}^{2}\right)$. Peripherin intensity measurements were taken in ImageJ using a $7.5 \mu \mathrm{m}^{2}$ ROI centered over the cell soma. Antibodies used in this study: rabbit anti-GDE2, 1:1000 (Covance); goat anti-Choline Acetyltransferase, 1:100 (Millipore AB144P); mouse anti-NeuN, 1:200 (Millipore MAB377); mouse anti-GFAP, 1:500 (BD Pharmingen 556328); rabbit anti-Neurofilament-H, 1:500 (Millipore AB1989); rabbit anti-Peripherin, 1:400 (Millipore AB1530); rabbit anti-Iba1, 1:500 (Wako 019-19741); rat anti-Lamp2, 1:500 (DSHB ABL-93); rat anti-CathepsinD, 1:500 (R\&D Systems MAB1029).

\section{Motor neuron quantification}

Motor neurons were quantified from paraffin sections of lumbar (L3-L5) spinal cord. Alpha $\left(\mathrm{ChAT}^{+} / \mathrm{NeuN}^{+}\right)$ and gamma $\left(\mathrm{ChAT}^{+} / \mathrm{NeuN}^{-}\right)$motor neuron numbers were averaged from a minimum of 15 sections and a minimum of 140 neurons per animal to ensure accurate sampling of heterogeneously distributed motor neurons. Total neurons counted per time point: 13 months: control $=2249$, Gde2 $\mathrm{KO}=1573 ; 6$ months: control $=1674$, Gde $2 \mathrm{KO}=950$. The LMC was defined as all neurons in the lateral aspect of spinal lamina 7 . The MMC was defined as all neurons in the medial portion of spinal lamina 8 . 


\section{Lipofuscin imaging}

Autofluorescent lipofuscin particles were imaged in unstained paraffin sections on a Zeiss LSM 700 using a $405 \mathrm{~nm}$ excitation laser and a long-pass $505 \mathrm{~nm}$ emission filter. Lipofuscin puncta were quantified from a single, in-focus $0.7 \mu \mathrm{m}$ z-plane from neurons in the ventral horn. Lipofuscin spectra were measured from in-situ deposits in paraffin embedded spinal cord sections using a Zeiss LSM 510 equipped with a metadetector and a near-infrared tunable pulsed femtosecond Ti:Sapphire laser (Chameleon Ultra II). Using 2photon excitation at $770 \mathrm{~nm}$, the emitted light was quantified in $10 \mathrm{~nm}$ increments from $367 \mathrm{~nm}$ to $699 \mathrm{~nm}$ with the meta-detector from the region of interest. The excitation spectrum was estimated by varying the 2-photon wavelength from $690 \mathrm{~nm}$ to $870 \mathrm{~nm}$ and measuring intensity of the emitted light filtered through a 500-550 $\mathrm{nm}$ band pass filter. The average intensity was then plotted using the approximate $1 \mathrm{P}$ wavelength (roughly $\lambda / 2$ ).

\section{Biochemistry}

Lysate Preparation: Freshly dissected lumbar spinal cord segments were lysed and separated into total and membrane fractions as previously described to detect Neurofilament and GDE2, respectively [9]. Sequential Solubilization: Dissected lumbar spinal segments were first homogenized in Tris Buffer (10 mM Tris, $150 \mathrm{mM}$ $\mathrm{NaCl}, \mathrm{pH} 7.5$ ) for $15 \mathrm{~s}$ with a Pellet Pestle (Kimble 749540). Samples were centrifuged 5000 x G for $5 \mathrm{~min}$. Supernatant (S1 fraction) was transferred to a new tube. The insoluble pellet was homogenized in Tris Buffer + $60 \mathrm{mM}$ Octyl $\beta$-D-glucopyranoside (Sigma O8001) for $15 \mathrm{~s}$ with a Pellet Pestle. Samples were centrifuged at 3000 x G for $5 \mathrm{~min}$. Supernatant (S2 fraction) was transferred to a new tube. Alpha Toxin Pull Down Assay: Alpha toxin from Clostridium septicum was expressed and purified as previously described [23] with the following modifications. An N-terminal HaloTag + C-terminal histidine tagged alpha toxin plasmid was transformed in Rosetta (DE3)pLysS Escherichia coli. Bacterial pellets were then resuspended in HaloTag protein purification buffer (50 mM HEPES, $150 \mathrm{mM}$ $\mathrm{NaCl}, 1 \mathrm{mM}$ DTT, $0.5 \mathrm{mM}$ EDTA, and 0.005\% IGEPAL CA-630), supplemented with $0.2 \mathrm{mg} / \mathrm{mL}$ lysozyme, $0.5 \mathrm{mg} / \mathrm{mL}$ DNase I. Cells were lysed with repeated rounds of freeze-thaw and centrifuged at 10,000 x G for $15 \mathrm{~min}$ at $4{ }^{\circ} \mathrm{C}$. The supernatant was incubated with TALON metal affinity resin (Clontech) overnight at $4{ }^{\circ} \mathrm{C}$. Alpha toxin was eluted in $50 \mathrm{mM} \mathrm{PB}, 300 \mathrm{mM}$ $\mathrm{NaCl}, 150 \mathrm{mM}$ imidazole, and the eluted sample was dialyzed and incubated with HaloLink resin for $1 \mathrm{~h}$ at room temperature. Proteins were then cross-linked with $0.05 \mathrm{mg} / \mathrm{mL}$ DSS. Soluble protein extract from
WT and Gde2 $\mathrm{KO}$ mice were incubated with the crosslinked alpha toxin overnight at $4{ }^{\circ} \mathrm{C}$, and captured proteins were eluted from the alpha toxin using 2\% SDS. Western Blot: Samples were run on $10 \%$ SDS-PAGE in Tris-glycine buffer. Proteins were transferred to PVDF membrane, washed with TBST, blocked with 5\% milk, and probed with the desired antibodies: rabbit anti-GDE2 (Convance 1:1000), rabbit anti-Neurofilament H (Millipore AB1989), mouse anti-Actin (Millipore MAB1501R); rabbit antiGlypican 1 (Abcam AB55971), rabbit anti-Glypican 4 (Immundiagnostik AH1007.2), goat anti-Glypican 6 (R and D Systems AF1053), rabbit anti-Na/K ATPase (Abcam AB76020), rabbit anti-GAPDH (Cell Signaling 8884). Blots were developed using HRP-conjugated secondary antibodies (Jackson Immunoresearch) with a chemiluminescent substrate. Densitometry measurements were made with ImageJ.

\section{Mass spectrometry}

Isolated gel pieces were subjected to a modified in-gel trypsin digestion procedure [24]. Gel pieces were dehydrated with acetonitrile for $10 \mathrm{~min}$ and then completely dried in a speed-vac. Gel pieces were rehydrated with $50 \mathrm{mM}$ ammonium bicarbonate solution containing $12.5 \mathrm{ng} / \mu \mathrm{l}$ modified sequencing-grade trypsin (Promega) at $4{ }^{\circ} \mathrm{C}$. The excess trypsin solution was removed and replaced with $50 \mathrm{mM}$ ammonium bicarbonate solution, and samples were then placed in a $37{ }^{\circ} \mathrm{C}$ room overnight. Peptides were later extracted by removing the ammonium bicarbonate solution, followed by one wash with a solution containing $50 \%$ acetonitrile and 1\% formic acid and dried. Samples were reconstituted in $5-10 \mu \mathrm{l}$ of HPLC solvent A (2.5\% acetonitrile, $0.1 \%$ formic acid). A nano-scale reverse-phase HPLC capillary column was created by packing $2.6 \mu \mathrm{m} \mathrm{C18} \mathrm{spherical} \mathrm{silica} \mathrm{beads} \mathrm{into} \mathrm{a} \mathrm{fused}$ silica capillary $(100 \mu \mathrm{m}$ inner diameter $\mathrm{x} \sim 30 \mathrm{~cm}$ length) with a flame-drawn tip [25]. After equilibrating the column each sample was loaded via a Famos auto sampler (LC Packings) onto the column. A gradient was formed and peptides were eluted with increasing concentrations of solvent B $(97.5 \%$ acetonitrile, $0.1 \%$ formic acid). As peptides eluted they were subjected to electrospray ionization and then entered into an LTQ Orbitrap Velos Pro ion-trap mass spectrometer (Thermo Fisher Scientific). Peptides were detected, isolated, and fragmented to produce a tandem mass spectrum of specific fragment ions for each peptide. Peptide sequences were determined by matching protein databases with the acquired fragmentation pattern using Sequest (Thermo Fisher Scientific) [26]. All databases include a reversed version of all the sequences and the data was filtered to between a one and two percent peptide false discovery rate. 


\section{Electrophysiology}

Animals were anesthetized under isofluorane anesthesia and body temperature maintained at $37{ }^{\circ} \mathrm{C}$ with a heating pad. A subdermal ground electrode was positioned in the upper back. Recordings were made with a PowerLab signal acquisition platform (ADInstruments). Motor Nerve Conduction Study (MNCS): Compound Motor Action Potentials (CMAPs) were obtained from the animal's right hindpaw. Platinum subdermal needle electrodes (Grass Instruments) were placed in plantar foot pads and stimulating electrodes were placed into the sciatic notch. The average of 5 CMAPs evoked with supramaximal stimulation was recorded. Motor Unit Number Estimation: The lower hindlimb was fitted with a circumferential surface electrode (CareFusion 019439300) lined with electroconductive gel (Parker Laboratories 15-60). Sequentially increasing stimulation was delivered with needle electrodes positioned in the sciatic notch until discrete CMAPS were observed. The first 10 stable motor units were recorded per animal followed by the supramaximal CMAP. Both hindlimbs of each animal were tested. Sensory Nerve Conduction Study (SNCS): Sensory Nerve Action Potentials (SNAPs) were recorded by placing needle electrodes in the dorsal aspect of the proximal tail and stimulating $5 \mathrm{~cm}$ distally. SNAP width is the time required for the SNAP waveform to return to baseline, and conduction velocity is calculated by dividing the recording distance $(5 \mathrm{~cm})$ by the distal latency.

\section{Behavior}

Mouse behavioral tests were performed at the Johns Hopkins University Brain Science Institute Behavioral Core. Male mice (10 WT and 10 Gde2 KO) were followed longitudinally with evaluation at 6 months and 13 months. Tests were performed sequentially; first grip strength, then open field followed by heat sensitization. Each test was done on a different day to reduce animal stress and fatigue. Electrophysiological experiments (described above) were performed after the behavior at each time point. To minimize variability, tests were only performed by 1 person between the hours of 11 am and $4 \mathrm{pm}$ in the light cycle. WT and KO animals were housed and tested together with unrestricted access to food and water. Prior to the first test at each time point, animals were handled by the experimenter for one hour on 5 consecutive days. Open Field: Individual animals were recorded for $30 \mathrm{~min}$ while they explored an open field activity chamber (Photobeam Activity System, San Diego Instruments). Movement was measured as disruptions in a grid of infrared beams lining the base of the chamber. During the recording, the chambers were enclosed in ventilated, light-proof cabinets. Grip Strength: Grip strength was measured by lifting the animal by the tail so its forelimbs or hindlimbs can grab the grid of the grip strength meter (Grip Strength Test,
IITC Life Science). When the animal is withdrawn, the force of the grip is recorded by a force transducer. In a session, each animal is tested 5 times with at least a 30 min rest in the home cage in between measurements. Heat Sensitization: Animals are habituated in clear plexiglass enclosures resting on an elevated glass platform heated to $32{ }^{\circ} \mathrm{C}$ (Plantar Test Analgesia Meter 390G, IITC Life Science). Latency is recorded as the interval between activating a heat lamp under the rear right paw and withdrawal of the paw from the targeted position. Per session, each animal is tested 7 times with at least $30 \mathrm{~min}$ of rest on the platform between measurements.

\section{Statistical analysis}

All graphs represent mean \pm SEM. Longitudinal behavior experiments compared across multiple time points were analyzed with a two-way Analysis of Variance (ANOVA) with repeated measures. All other quantitative data was analyzed with an unpaired Student's t-test. Significance level is a value of $p \leq 0.05$. Cell counts in Fig. 6e, h, and Additional file 1: Figure S2 are all normalized to the mean of the control values for clarity of presentation. Statistical analysis was performed on the raw data. The n-numbers as stated in the figure legends refer to individual animals processed and analyzed equivalently between the experimental groups.

\section{Results}

\section{GDE2 is expressed in the postnatal spinal cord}

To assess postnatal expression of Gde2, we performed fluorescent in-situ hybridization (FISH) on lumbar spinal cord sections using antisense and sense probes directed against the 3' untranslated region (UTR) of Gde2. In 1 month old $G d e 2^{+/+}$mice, Gde2 mRNA expression is widespread throughout the spinal cord. We detect Gde2 transcript in all spinal laminae, lateral and ventral funiculi, and the dorsal columns (Fig. 1a). This cellular distribution, particularly in the white matter, implies that postnatal Gde2 expression is not confined to neuronal subtypes. We observe clear Gde2 expression in large diameter neurons in the ventral horn (Fig. 1b), small diameter neurons in the dorsal horn (Fig. 1c), and glial soma in the white matter (Fig. 1d). Similar analysis using the corresponding sense probe showed no signal in adjacent sections confirming specificity of the antisense probe (Fig. 1e). This expression pattern is consistent with published cell-type expression databases documenting broad Gde2 expression in the postnatal CNS $[27,28]$.

To confirm that GDE2 protein is produced postnatally, we performed western blots of 1 month and 19 month lumbar spinal cord lysates using an antibody generated against GDE2. Gde $2^{+/+}$lysates show a strong band at the predicted size that is absent in Gde $2^{-/-}$littermates (Fig. 1f). Taken together, these observations indicate that GDE2 

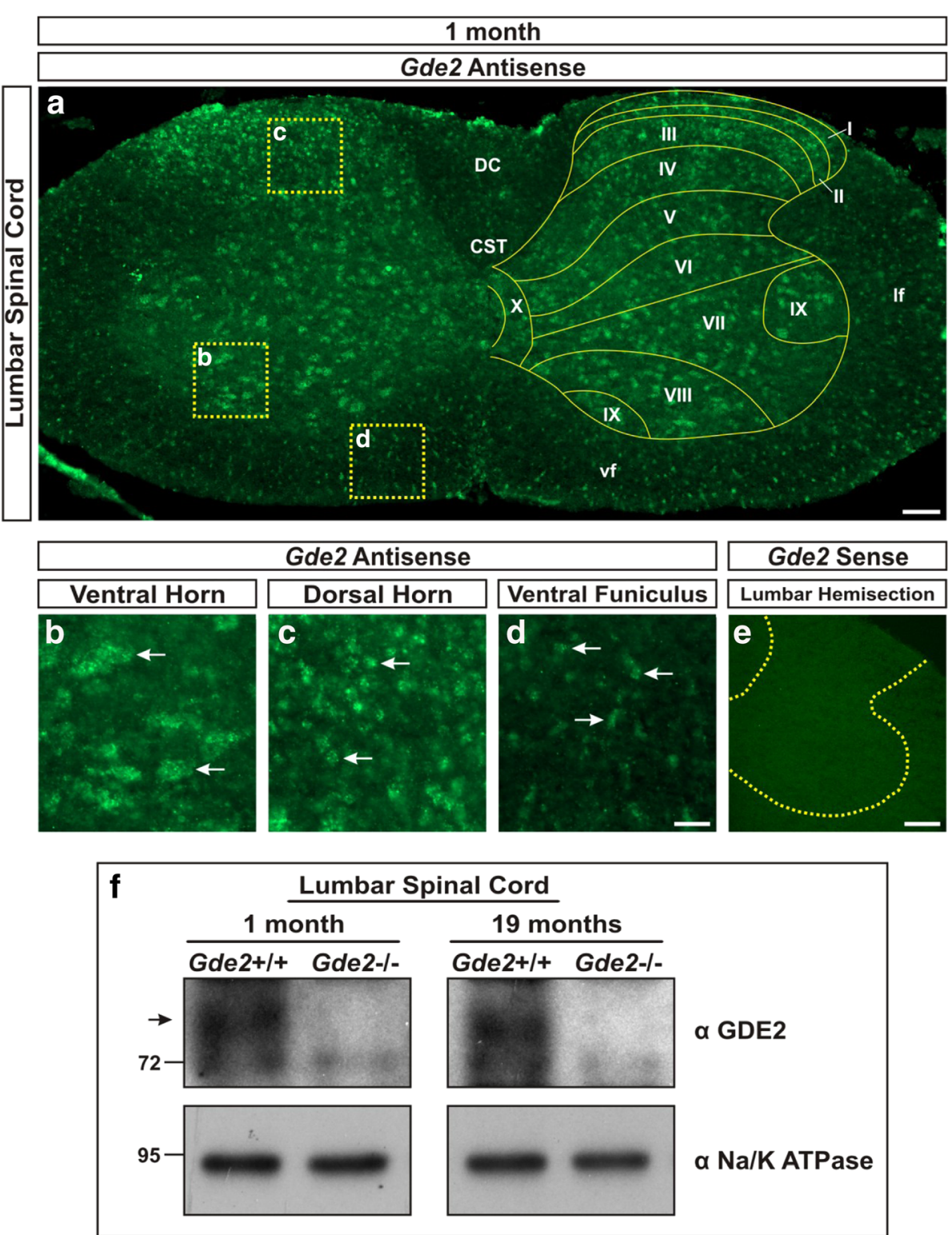

Fig. 1 Gde2 mRNA and protein are expressed in the postnatal spinal cord. a Paneled epifluorescent image of fluorescent in-situ hybridization (FISH) using a Gde2 antisense probe showing broad expression in all spinal laminae (labeled I to X), as well as the corticospinal tract (CST), dorsal columns (DC), lateral funiculus (If), and ventral funiculus (vf). Scale bar $=100 \mu \mathrm{m}$. b-d Magnified regions indicated in panel A showing Gde2 expression in large diameter motor neurons (B), small diameter neurons (C), and glia (D). Arrows mark examples. Scale bar $=35 \mu \mathrm{m}$. e Gde2 sense probe shows no signal in the lumbar spinal cord. Dashed yellow lines = boundary between grey and white matter. Scale bar $=150 \mu \mathrm{m}$. $\mathbf{f}$ Western blot visualizing GDE2 protein (80kD band) in WT and not Gde2 KOs. $n=3$

expression continues throughout life, suggesting ongoing roles for GDE2 in the adult nervous system.

\section{Gde2 null animals present degenerative pathology}

To investigate the postnatal roles of GDE2, we analyzed transverse sections of $\mathrm{Gde}^{+/+}$and $\mathrm{Gde}^{-/-}$lumbar spinal cords at 6 weeks and 19 months, two time points which allow the comparison between early and late stage pathology. Using Hematoxylin \& Eosin (H\&E) stains to visualize cellular and interstitial morphology, we find neurons in the Gde $2^{-/-}$spinal cord are filled with intracellular vacuoles that are not apparent in wild-type (WT) animals (Fig. 2a-d). At 19 months, Gde2 $2^{-/-}$motor neurons are heavily vacuolated, with shrunken and condensed somas, and have separated from their adjoining neuropil (Fig. 2d). We quantified the incidence of this intracellular vacuolization among neurons in the ventral horn. At 6 weeks, only $3.50 \pm 1.09 \%$ of WT neurons contain vacuoles compared to $14.02 \pm 3.39 \%$ in $G d e 2^{-/-}$ mice. At 19 months, vacuolization among WT neurons 

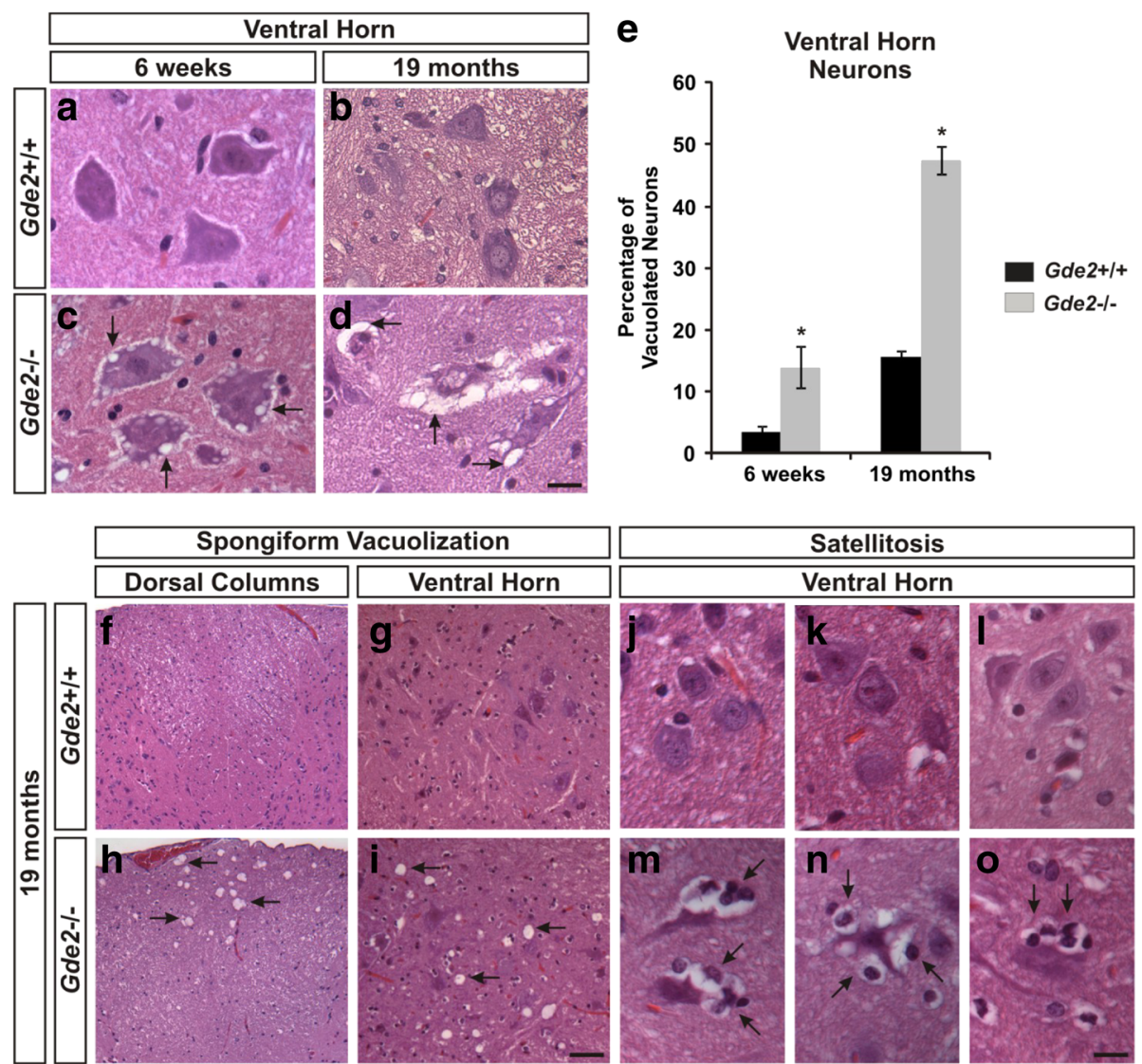

Fig. 2 Gde2 null animals develop vacuolization and satellitosis. a-d H\&E staining of transverse sections of lumbar spinal cord. Arrows in c, d show progressive intracellular vacuolization. Scale $b a r=20 \mu \mathrm{m}$. e Quantification of increased neuronal vacuolization in large diameter ventral horn neurons of the Gde2 KO. Graph represents mean \pm SEM. 6 weeks ${ }^{*} p=0.022,19$ months ${ }^{*} p=<0.001$, Student's $t$ test, $n=3$. $\mathbf{f}-\mathbf{i}$ Arrows mark large spongiform vacuoles in the dorsal columns and ventral horn. Scale bar $=60 \mu \mathrm{m}$. $\mathbf{j}$-o Arrows mark satellitosis of ventral horn neurons of the Gde2 KO. Scale bar $=20 \mu \mathrm{m} . n=3 \mathrm{WT}, 4 \mathrm{KO}$

climbs to $15.68 \pm 1.03 \%$ and the incidence in the $\mathrm{KO}$ rises to $47.41 \pm 2.28 \%$ (Fig. 2e). In addition, aged Gde $2^{-/-}$ animals exhibit prominent spongiform vacuoles in the extracellular space of the dorsal columns and ventral grey matter (Fig. 2f-i). We also observe instances of satellitosis, the surrounding of neurons by smaller nuclei that are presumptive macrophages in the processes of phagocytosis (Fig. 2j-o) [29]. These phenotypes point to a pronounced, progressive neuronal degeneration in the absence of GDE2.

\section{Gde2 deletion causes astrocytosis and microgliosis}

Prompted by the pronounced satellitosis, we next analyzed $G d e 2^{-l-}$ spinal cords for additional glial pathology. Gliosis refers to the inflammatory reaction of glial cells, mainly astrocytes and microglia, in response to injury or disease and is a strong indicator of degeneration. As astrocytes and microglia respond to disease conditions, they undergo distinct morphological transitions. Inflammatory astrocytes expand and enumerate their processes while microglia truncate their processes and form multicellular aggregates [30, 31]. We analyzed astrocyte morphology by staining for Glial Fibrillary Acidic Protein (GFAP). At 6 weeks, no appreciable differences are detected in the ventral horn of $G d e 2^{-1-}$ mice (Fig. 3a and b); however, by 19 months, astrocytes in the Gde2 -I- animals show intensified GFAP immunoreactivity and broadened processes (Fig. 3c and d). We quantified the differences in astrocyte morphology by calculating the area of all $\mathrm{GFAP}^{+}$processes within a $150 \mu \mathrm{m}^{2}$ region of interest (ROI) centered in either the ventral grey matter or white matter (Fig. 3d). The area of the GFAP ${ }^{+}$ processes divided by the area of the ROI yields the GFAP area fraction. At 6 weeks, the WT and $\mathrm{KO}$ values for GFAP area fraction were $0.22 \pm 0.12 \%$ and $0.11 \pm$ $0.08 \%$ in grey matter and $10.21 \pm 3.97 \%$ and $8.29 \pm 3.12 \%$ in white matter, respectively. At 19 months of age, the WT and $\mathrm{KO}$ values were $0.40 \pm 0.22 \%$ and $22.26 \pm 4.15 \%$ in grey matter and $13.86 \pm 4.34 \%$ and $41.07 \pm 6.40 \%$ in white matter, respectively (Fig. 3e). Resting $\mathrm{Iba}^{+}$ 


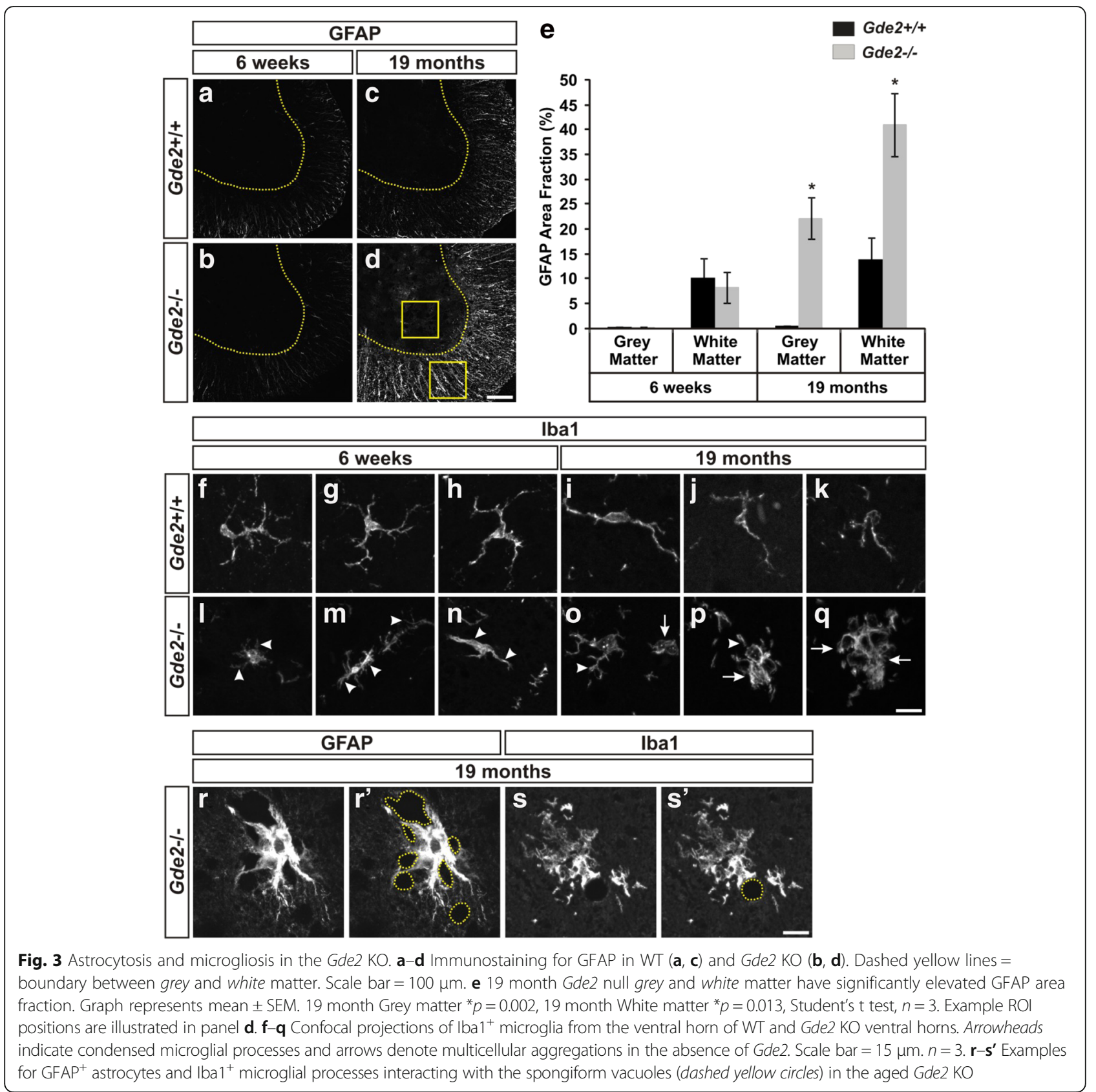

microglia exhibit a very stereotyped morphology; they are evenly spaced with multiple thin branches extending from the soma (Fig. $3 \mathrm{f}-\mathrm{k}$ ). In contrast, microglia in the 6 week old Gde2 KO spinal cord display shortened, condensed processes indicative of microglial activation (Fig. 3l-n). By 19 months, the reactive morphologies worsen and large microglial aggregates form in the ventral and lateral funiculi (Fig. 3o-q). In addition, we note that the inflammatory glia often associate with the spongiform abscesses in the grey and white matter (Fig. 3r-s'). Taken together, Gde2 ablation produces prominent astro- and microgliosis, which suggests a progressive neuropathology in the Gde2 $\mathrm{KO}$ spinal cord.

Gde2 KO neurons exhibit cytoskeletal accumulation and mislocalization

The neuronal pathology in the spinal cord motivated us to screen $G d e 2^{-/-}$animals for cytoskeletal defects prevalent in neurodegenerative disease. In neurons, one of the principal cytoskeletal components is Neurofilament, and of the three main neurofilament isoforms (NF-L, NF-M, $\mathrm{NF}-\mathrm{H})$, irregularities in NF-H expression have been most 
frequently associated with neurodegeneration [32-34]. In Gde2 null animals at 6 weeks, we observe increased NF-H immunoreactivity within dilated neuronal processes (Fig. 4a-f). By 19 months, the magnitude of the cytoskeletal accumulation has risen in the ventral horn (Fig. $4 \mathrm{~g}-\mathrm{l}$ ). To more accurately quantify the NF-H increase, we performed western blots of 17 month lumbar spinal cord lysates. We found a $2.25 \pm 0.50$ fold increase of NF-H protein expression in Gde2 null spinal cords compared with WT (Fig. 4m). Peripherin is an intermediate filament expressed in motor, sensory, and sympathetic neurons and has also been reported to undergo degeneration dependent increases [35]. Unlike the bulk accumulation of $\mathrm{NF}-\mathrm{H}$, neurons lacking Gde2 amassed peripherin protein within their somas at 6 weeks (Fig. $4 \mathrm{n}$ and o). At 19 months, we detect the majority of peripherin immunoreactivity in the ventral and lateral funiculi within axons. WT axons distribute peripherin in discrete bundles; Gde2 ${ }^{-/-}$axons traffic peripherin to the interior perimeter of the axon (Fig. 4p-s"). Considering the importance of regulating cytoskeletal proteins for intracellular trafficking, the dysregulation of NF-H and peripherin pose a severe impediment to normal cellular function and likely reflect diminished neuronal health.
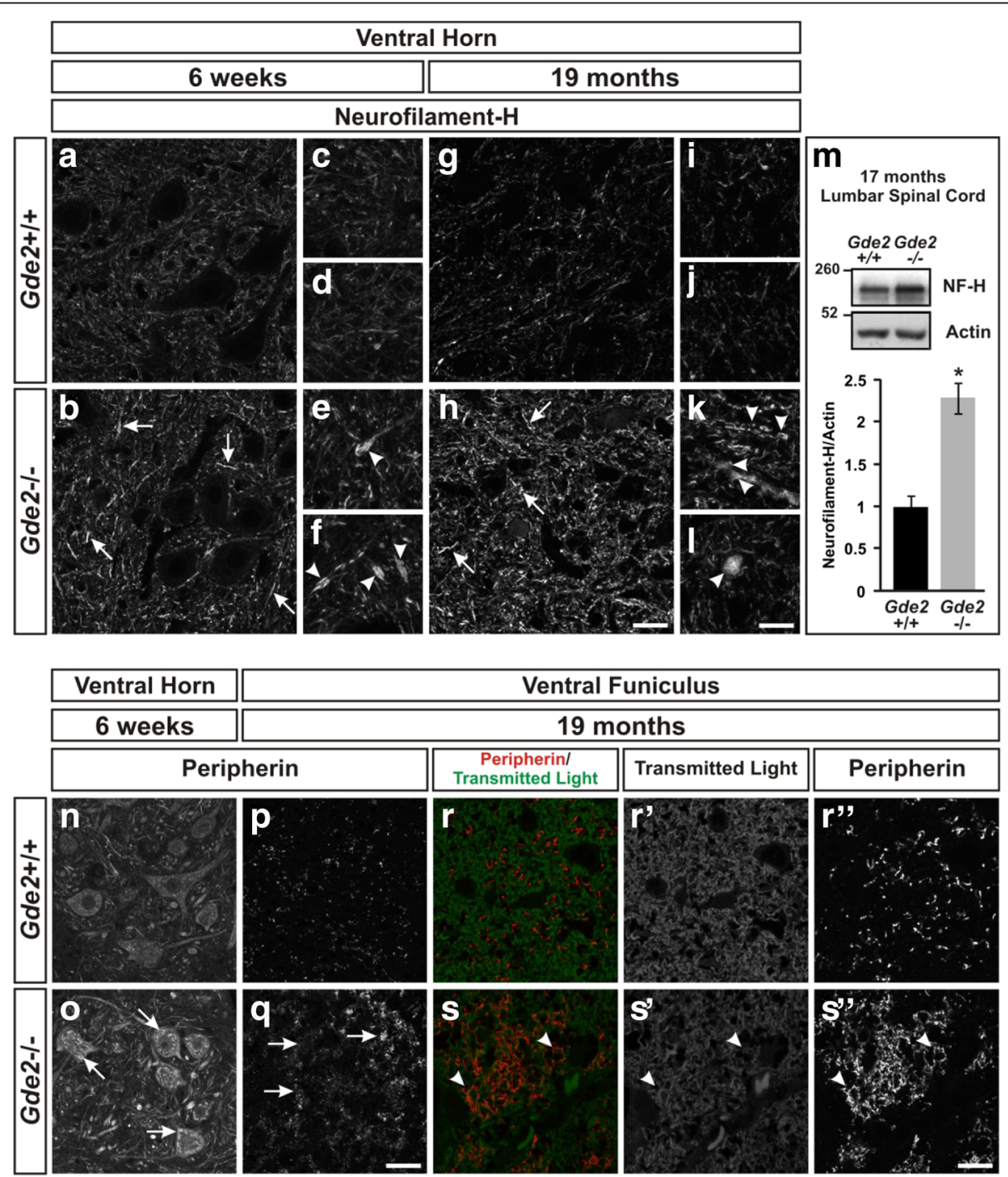

Fig. 4 Gde2 KO neurons show cytoskeletal dysregulation. a-I Neurofilament-H immunostaining in the ventral horn. Arrows indicate cytoskeletal accumulation in the absence of Gde2. Arrowheads mark spheroid deposits of Neurofilament-H within dilated neuronal processes. Scale bar $\mathbf{a}, \mathbf{b}, \mathbf{g}$, $\mathbf{h}=25 \mu \mathrm{m}$. Scale bar $\mathbf{c}-\mathbf{f}, \mathbf{i}-\mathbf{I}=15 \mu \mathrm{m}$. $\mathbf{m}$ Western blot quantifying increased NF-H protein. Graph represents mean \pm SEM, ${ }^{*} p=0.004$, Student's $\mathrm{t}$ test, $n=3$ WT, 4 KO. $\mathbf{n}-\mathbf{q}$ Gde2 null neurons accrue peripherin protein. Arrows indicate peripherin tendrils in the cell body at 6 weeks and axons at 19 months. Scale bar $=25 \mu \mathrm{m}$. $\mathbf{r}$-s" Arrowheads denote axonal accumulation of peripherin enriched around the perimeter of the axon. Scale bar $=10 \mu \mathrm{m} . n=3$ 
Gde2 KO neurons have accelerated lipofuscin deposition The degenerative accrual of NF-H and peripherin led us to investigate whether Gde2 deletion promotes the pathologic accumulation of lipids as well as protein. Sudan Black B is a lipophilic dye that intercalates into lipid rich domains [36]. At 19 months, Gde $2^{-/-}$neurons in the ventral horn have pronounced perinuclear deposits that strongly take up Sudan Black B that are not detectable in
Gde $2^{+/+}$neurons (Fig. 5a-d). These particles are characteristic of lipofuscin, an accumulation of lipids and undigested cellular debris, namely proteins, which collect as discrete cytosolic puncta during normal aging [37, 38]. Lipofuscin can be specifically visualized as autofluorescent granules with ultraviolet absorbance and broad emission in unstained tissue sections [36]. At 6 weeks of age, we detect an average of $6.68 \pm 2.28$ autofluorescent lipofuscin
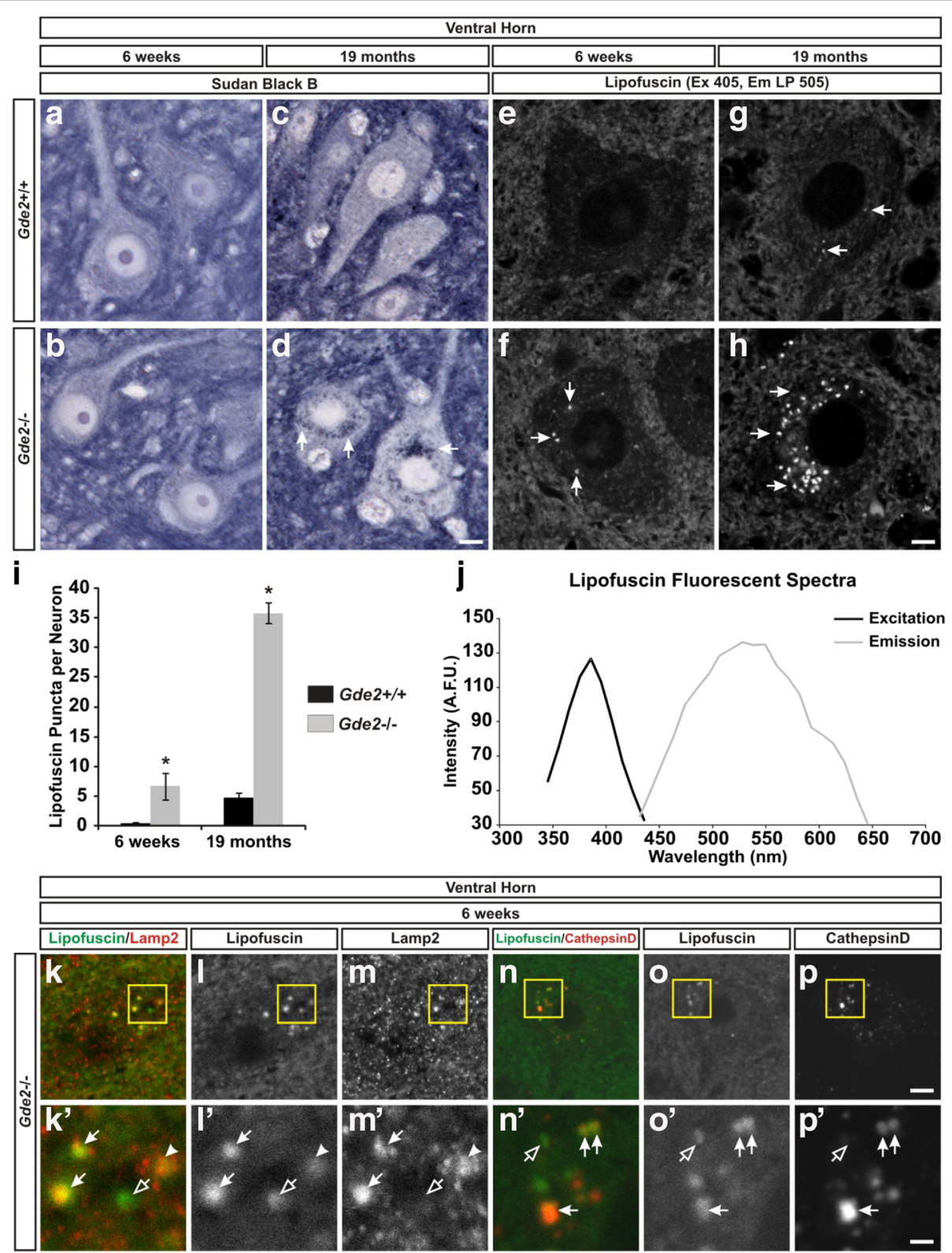

Fig. 5 Lipid deposition in Gde2 null neurons. a-d Sudan Black B darkly stains lipid deposits in motor neurons of the aged Gde2 KO (arrows). Scale $\operatorname{bar}=7 \mu \mathrm{m} . n=3$. e-h Lipofuscin (arrows) is visualized as autofluorescent granules using ultraviolet excitation (405 nm) and a long pass emission (LP 505) filter. Scale bar $=10 \mu \mathrm{m}, n=3$. i Quantification of elevated lipofuscin granules at 6 weeks ${ }^{*} p=0.028$ and 19 months ${ }^{*} p<0.001$, Student's $t$ test, $n=3$. Graph represents mean \pm SEM. $\mathbf{j}$ Lipofuscin granules have an ultraviolet excitation maxima centered at $390 \mathrm{~nm}$, and a broad emission curve peaking at $530 \mathrm{~nm} . \mathbf{k}, \mathbf{I}, \mathbf{m}, \mathbf{n}, \mathbf{0}, \mathbf{p}$ Lipofuscin association with lysosomes labeled by Lamp2 or CathepsinD. Scale bar = $4.25 \mu \mathrm{m}$. $\mathbf{k}^{\prime}, \mathbf{I}^{\prime}, \mathbf{m}^{\prime}, \mathbf{n}^{\prime}$, $\mathbf{o}^{\prime}, \mathbf{p}^{\prime}$ Magnification of boxed regions in panels $\mathbf{k}-\mathbf{p}$. Lipofuscin is fully or partially colocalized with (filled arrows), surrounded by (arrowheads), or devoid of (open arrow) lysosomal signal. Scale bar $=1.5 \mu \mathrm{m} . n=4$ 
granules per neuron in the $\mathrm{KO}$ and $0.47 \pm 0.18$ granules in control neurons (Fig. 5e, f and i). At 19 months, numerous bright autofluorescent granules are evident in ventral horn neurons in Gde2 $\mathrm{KO}$ animals compared with WT, $35.82 \pm 1.69$ versus $4.83 \pm 0.84$ granules, respectively (Fig. 5g-i). These deposits have a spectral excitation and emission profile consistent with lipofuscin (Fig. 5j). Lipofuscinogenesis is nucleated by the lysosome, wherein reactive hydroxyl radicals form aldehyde cross linkages between the undigested macromolecules [38]. If the autofluorescent granules seen in the Gde2 KO are lipofuscin, we predicted that a subset should colocalize with lysosomal markers. Indeed, we find that some lipofuscin granules are fully or partially colocalized with Lamp2 $^{+}$or CathepsinD ${ }^{+}$lysosomes while others are juxtaposed, and some have no lysosomal signal (Fig. 5k-p'). Early accumulation of lipofuscin is an indicator of increased cellular stress and can presage neurodegeneration in disease conditions [39]. The advanced deposition of lipofuscin granules in $\mathrm{Gde}^{-/-}$animals provides further evidence that GDE2 is essential for neuronal health.

\section{Gde2 ablation causes progressive motor neuron loss}

The collective histology in the Gde $2^{-/-}$spinal cord signifies a progressive neuropathology that worsens from 6 weeks to 19 months afflicting neurons in the ventral horn of the spinal cord. We next sought to understand if and how these pathologies impact neuronal survival. Though the pathology affects many neuronal subtypes in the ventral horn, we focused on motor neurons as their cell death is an integral component of many neurodegenerative diseases. We assessed the survival of alpha motor neurons $(\alpha)$ and gamma motor neurons $(\gamma)$ in the lateral and medial motor columns (LMC and MMC) of the lumbar spinal cord. Alpha motor neurons innervate force generating skeletal muscle while gamma motor neurons innervate intrafusal muscle fibers to control proprioceptive sensory feedback [40]. Both types of motor neurons express Choline Acetyltransferase (ChAT) but only alpha motor neurons coexpress NeuN (Fig. 6a-b") [41]. To understand how the progressive neuropathology that develops from 6 weeks to 19 months affects cell survival, we quantified motor neurons at 2 intermediate time points, 6 months and 13 months. In the LMC, which innervates limb muscles, we find a marked decrease in both alpha and gamma neurons (Fig. 6c-d"). At 6 months, we register a $45.84 \pm 4.75 \%$ decrease in alpha motor neurons and a $45.07 \pm 9.75 \%$ decrease in gamma motor neurons (Fig. 6e). By 13 months, these deficits grow to $61.91 \pm$ $1.21 \%$ and $57.83 \pm 1.87 \%$ for alpha and gamma, respectively (Fig. 6e). In the MMC, which innervates the axial muscles of the trunk, no decreases in alpha and gamma motor neurons are detected at 6 months; however, significant reductions are evident by 13 months of age with alpha motor neurons falling $35.83 \pm 6.57 \%$ and gamma motor neurons dropping by $42.25 \pm 3.03 \%$ in the Gde2 KO (Fig. 6f-h). Thus, deletion of Gde2 results in the progressive loss of spinal motor neurons as the animal ages.

\section{Gde2 KO animals undergo peripheral restructuring without impaired peripheral nerve conduction}

To determine if any physiological consequences result from the motor neuron deficits in the Gde2 $\mathrm{KO}$, we carried out a longitudinal electrophysiological study of peripheral nerve function in a cohort of $10 \mathrm{WT}$ and 10 Gde2 KO mice. Considering the significant motor neuron loss observed at 6 months and 13 months, we performed Motor Nerve Conduction Studies (MNCS) at these time points to screen for defects in peripheral nerve physiology. MNCS record a Compound Motor Action Potential (CMAP) from the plantar foot muscles after stimulating the sciatic nerve (Fig. 7a). The latency and amplitude of the CMAP convey the efficiency of action potential conduction and strength of the neuromuscular connection, respectively [42]. At 6 and 13 months, Gde2 $\mathrm{KO}$ animals displayed no changes in CMAP waveforms (Fig. 7b), indicating preserved peripheral nerve function in the absence of Gde2.

We next measured the size of the individual motor units, defined as a motor axon and all the muscle fibers it innervates, using Motor Unit Number Estimation (MUNE). MUNE records from all the muscles of the lower hindlimb and utilizes sequential increases in submaximal stimulation to reveal individual CMAPs in a quantal manner, each representing one motor unit. After recording the amplitude of several motor units and dividing their average into the supramaximal CMAP, the number of motor units in the recording field can be estimated $[43,44]$. We recorded the first ten stably detectable CMAPs from 13 month WT and Gde2 nulls (Fig. 7c). The average motor unit amplitude increases from $0.0274 \pm$ $0.005 \mathrm{mV}$ in the WT to $0.0781 \pm 0.015 \mathrm{mV}$ in $\mathrm{Gde}^{-/-}$animals (Fig. $7 \mathrm{~d}$ ). There is no change in the supramaximal CMAP; consequently, the MUNE values for WT and Gde2 nulls are $96.48 \pm 19$ and $27.14 \pm 5.23$ motor units respectively (Fig. 7d). The decrease in motor units in Gde2 ${ }^{-/}$animals is consistent with peripheral restructuring observed during long-term progressive motor neuron loss, which involves reinnervation of denervated muscle fibers by sprouting collaterals [45].

\section{Gde2 KO animals have impaired motor performance}

Considering the neuronal loss, peripheral restructuring and histopathology of animals lacking GDE2, we measured the motor performance of our in-vivo cohort at 6 months and 13 months. When elevated by the tail, 

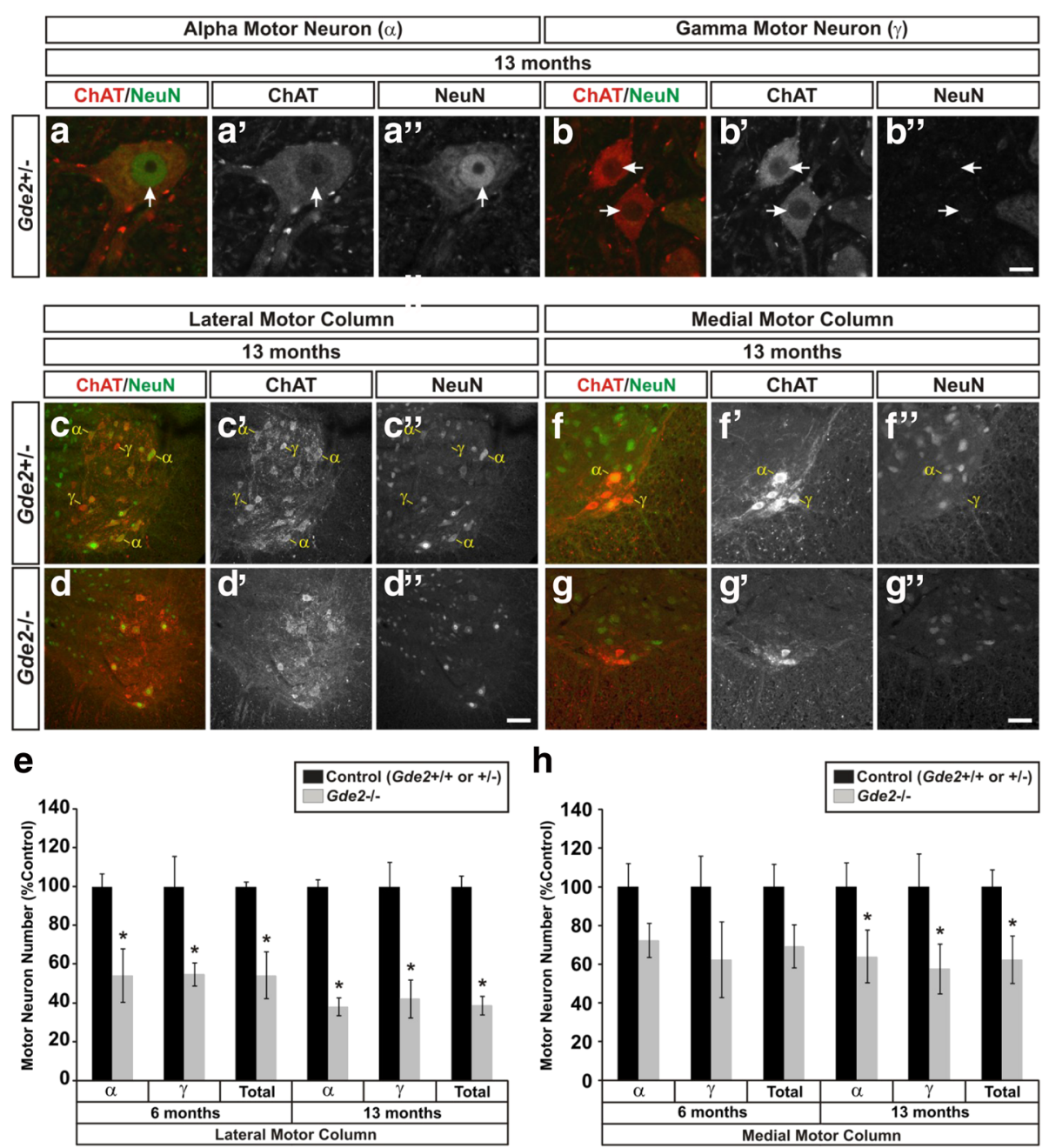

Fig. 6 Gde2 KO mice have progressive motor neuron loss. a-b" Example images of alpha (a) and gamma ( $\mathrm{a}$ ) motor neurons. Alpha motor neurons are $\mathrm{ChAT}^{+} / \mathrm{NeuN}^{+}$while gamma motor neurons are $\mathrm{ChAT}^{+} / \mathrm{NeuN}^{-}$. Arrows indicate position of the nucleus. Scale bar $=10 \mu \mathrm{m} . \mathbf{c}-\mathbf{d}^{\prime \prime}$ Representative images of motor neurons in the LMC labeled with ChAT and NeuN at 13 months. Example $a$ and $\gamma$ motor neurons are indicated. Scale $b a r=50 \mu \mathrm{m}$. e Quantification of LMC motor neuron loss. 6 months: $a^{*} p=0.001, \gamma{ }^{*} p=0.048$, Total ${ }^{*} p=0.003, n=3.13$ months: $a{ }^{*} p<$ $0.001, \gamma^{*} p=0.046$, Total ${ }^{*} p=0.001, n=5 . \mathbf{f}-\mathbf{g}^{\prime \prime}$ Images of $a$ and $\gamma$ motor neurons in the MMC at 13 months. $\mathbf{h}$ Graph quantifying MMC motor neuron decrements. 6 months: $a p=0.212, \gamma p=0.151$, Total $p=0.116, n=3.13$ months: $a^{*} p=0.002, \gamma{ }^{*} p<0.001$, Total ${ }^{*} p=0.002, n=5$. All graphs represent mean \pm SEM, Student's t test

WT mice extend their hindlimbs away from their abdomen (Fig. 8a and b); however, the aged Gde2 null mice display intermittent clasping of their hindlimbs consistent with motor neuropathy (Fig. 8c and d) [46]. Grip strength, the force that mice exert on a grid with their paws when lifted away [47], showed no difference at 6 months (Fig. 8e). However at 13 months, we observed a $31.52 \pm 3.11 \%$ and $35.44 \pm 3.63 \%$ decrease in forelimb and hindlimb grip strength, respectively (Fig. 8e). As with grip strength, we saw no changes in motor activity in an open field chamber [48] at 6 months but found a $73.47 \pm 14.95 \%$ decrease in fine movement at 13 months (Fig. 8f). Lastly, we measured heat sensitization, the animal's latency to withdraw its hindpaw from a noxious radiant heat source [48]. Successful completion of this task requires a functional sensorimotor reflex circuit, composed of a primary sensory neuron signaling to a motor neuron which in turn signals to the limb muscles. Gde2 KO mice have an increased latency to withdraw their paw $(5.51 \pm 0.31 \mathrm{~s}$ versus $3.91 \pm 0.52 \mathrm{~s}$ for the WT) as early as 6 months, and comparable delays are seen at 13 months of age (Fig. 8g), indicating deficits within the spinal sensorimotor reflex circuit. Considering the Gde2 KO's impaired heat sensitization, a task requiring sensory and motor function, we assayed primary sensory neurons of the dorsal root gangion (DRG) for evidence of pathology. We find that lumbar DRG neurons in the Gde2 KO display analogous pathology to motor neurons, including 

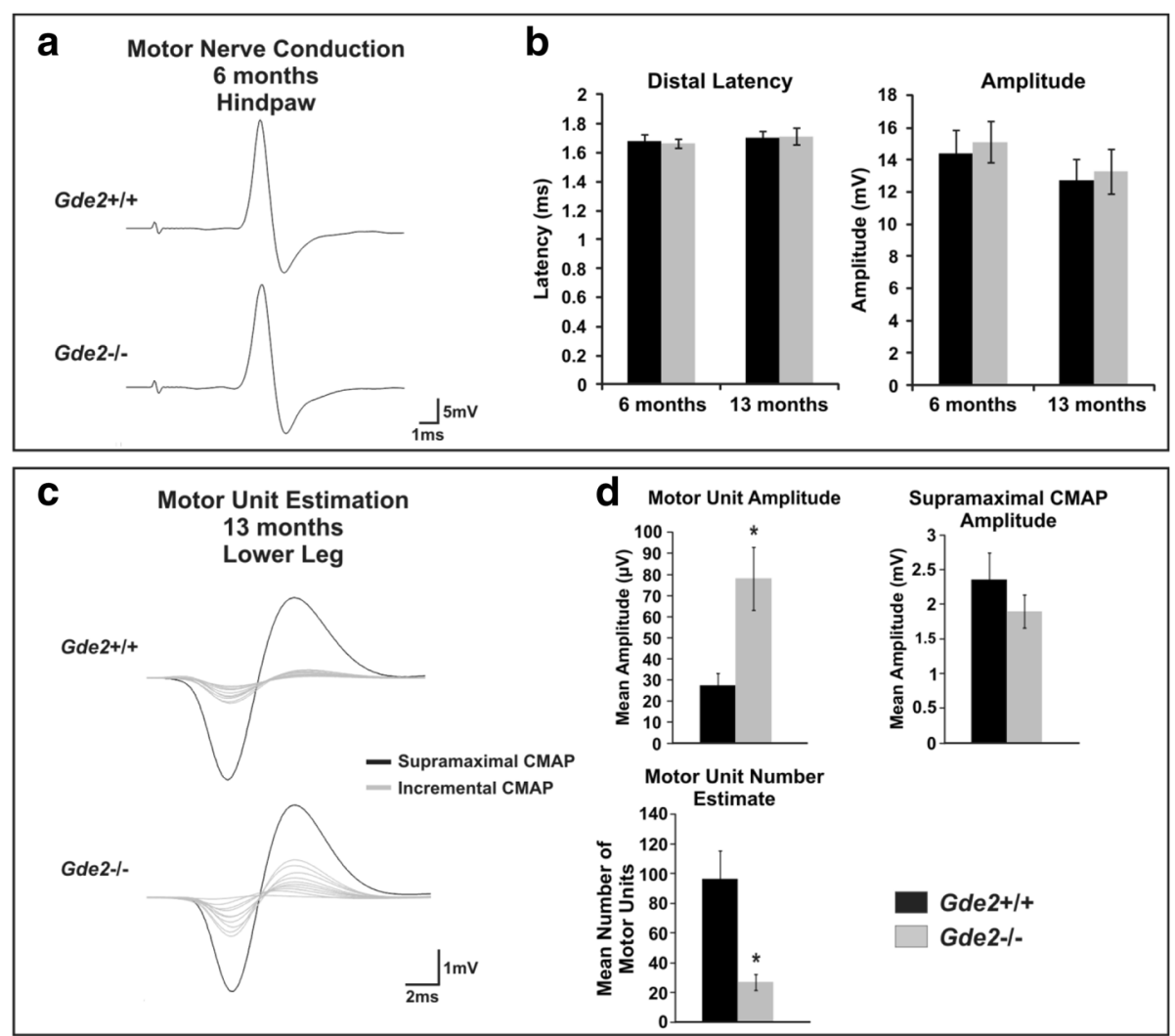

Fig. 7 Gde2 $\mathrm{KO}$ animals exhibit motor unit restructuring with equivalent peripheral conduction. a Example Compound Motor Action Potentials recorded from WT and Gde2 KO hindpaws following supramaximal stimulation to the sciatic nerve. $\mathbf{b}$ Graphs measuring Distal Latency: 6 months $p=0.413,13$ months $p=0.457$; and Amplitude: 6 months $p=0.356,13$ months $p=0.388, n=10$. c Motor Unit field recordings from lower hindlimb following incremental (grey traces) and supramaximal (black traces) stimulation of the sciatic nerve. $\mathbf{d}$ Graphs quantifying mean Motor Unit Amplitude ${ }^{*} p=0.002$, Supramaximal CMAP Amplitude $p=0.144$, and Motor Unit Number Estimate ${ }^{*} p=0.026, n=5$. All graphs represent mean \pm SEM, Student's t test

vacuolization, lipid accumulation, and cytoskeletal dysregulation. As with efferent motor nerve conduction (Fig. 7b), we saw no changes in afferent peripheral sensory nerve conduction. (Additional file 1: Figure S1). These collective observations suggest that loss of GDE2 results in progressive erosion of sensorimotor function in the adult animal.

\section{GDE2 is required postnatally for neuronal survival}

GDE2 is necessary during embryogenesis for promoting the differentiation of late-born alpha motor neurons within the limb-innervating LMC [8]. Aged Gde2 KO animals show losses in LMC alpha motor neurons beyond the embryonic decrement and also exhibit reductions in gamma motor neurons and MMC motor neurons, two populations whose development is not impacted by Gde2 deletion (Fig. 6e and h) [8]. These observations suggest that the degenerative loss of motor neurons in adult Gde2 ${ }^{-/-}$animals is not a latent effect of improper embryonic development. To test this hypothesis, we utilized Cre-lox approaches to ablate Gde2 after motor neuron differentiation, which is normally complete by E11.5. Specifically, a floxed conditional allele of Gde2 (Gde $\left.2^{\text {lox/- }}\right)$ was used in concert with an inducible $\mathrm{Cre}^{\mathrm{ER}}$ driven by the ubiquitously expressed ROSA promoter (ROSA:Cre ${ }^{\mathrm{ER}}$ ) [49], and 4-hydroxytamoxifen (4-OHT) was delivered to pregnant dams at E17.5.

We aged Gde $2^{\text {lox } /-} ; R O S A: C r e^{E R}$ and $G d e 2^{+/-} ; R O S A: C-$ $\mathrm{re}^{\mathrm{ER}}$ littermate controls to 6 weeks and first verified the efficient deletion of GDE2 at the functional and genetic level. Confirming the efficacy of temporal ablation after developmental neurogenesis is complete, the developmental reduction of LMC alpha motor neurons normally observed at 6 weeks in constitutive Gde2 nulls is not present in $G d e 2^{\text {lox } /-} ; R O S A: \mathrm{Cre}^{\mathrm{ER}}$ animals. Further, we verified the efficient ablation of the Gde2 conditional allele using a competitive PCR strategy $[8,50]$ that shows near complete removal of the Gde2 lox allele following 4-OHT administration (Additional file 1: Figure S2). We then analyzed these mice for the earliest signs of neurodegeneration exhibited by constitutive Gde2 nulls at this time point, i.e. vacuolization, increased 


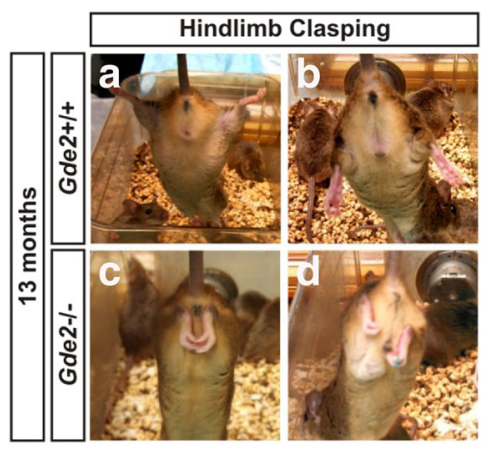
Open Field Activity Monitor
Fine Movement

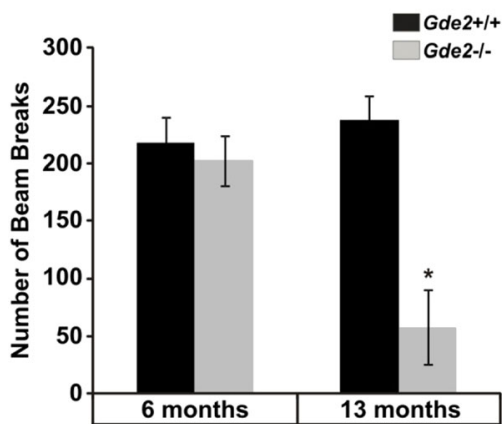

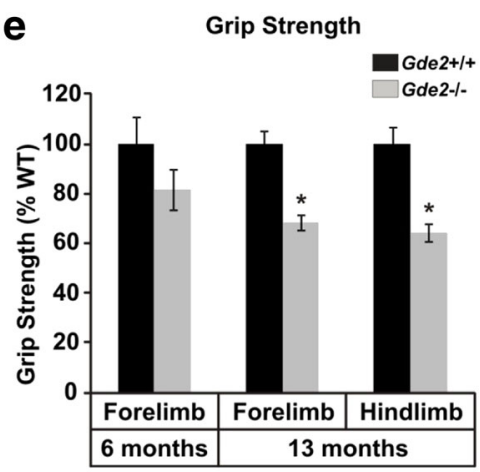

g
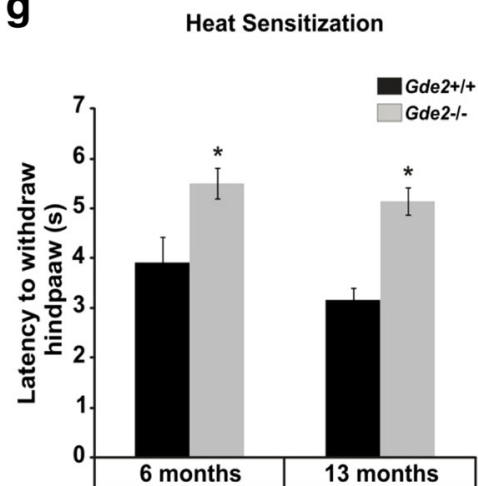

Fig. 8 Gde2 ablation causes progressive motor degeneration. a-d Aged Gde2 KO animals display hindlimb clasping. e Grip strength shows significant interaction with genotype and animal age $\left(F_{1,39}=9.016,{ }^{*} p=0.008\right)$ indicating progressive deterioration of $G$ de2 $\mathrm{KO}$ motor performance. f Fine movement in the Open Field Activity Monitor reveals significant interaction with genotype $\left(F_{1,39}=4.45,{ }^{*} p=0.049\right)$. $\mathbf{g}$ Heat sensitization shows significant increases at 6 months and 13 months in $G$ de2 $\operatorname{KOs}\left(F_{1,39}=19,749,{ }^{*} p<0.001, n=10\right)$. Graphs represent mean \pm SEM, 2-way repeated measures ANOVA, $n=10$

cytoskeletal protein, lipofuscin, and microgliosis. H\&E staining revealed increased vacuolization in $G d e 2^{\text {lox/- }}$ ;ROSA:Cre ${ }^{\mathrm{ER}}$ motor neurons that is not seen in Gde2 ${ }^{+/} ;$ROSA:Cre ${ }^{\mathrm{ER}}$ littermates (Fig. 9a and b). The incidence of vacuolization among ventral horn neurons rose from $10.25 \pm 3.10 \%$ in the Gde $2^{+/-} ; R O S A: \mathrm{Cre}^{\mathrm{ER}}$ mouse to $26.56 \pm 2.47 \%$ in the Gde $2^{\text {lox/- }} ; \operatorname{ROSA}: \mathrm{Cre}^{\mathrm{ER}}$ (Fig. 9c). We found that Gde $2^{\text {lox/- }} ; \operatorname{ROSA}: \mathrm{Cre}^{\mathrm{ER}}$ animals showed a substantial increase in somal peripherin immunoreactivity compared to controls (Fig. 9d and e). Mean peripherin intensity levels increased from $52.85 \pm 2.66$ artificial fluorescence units (A.F.U) in Gde $2^{+/-} ; R O S A: \mathrm{Cre}^{\mathrm{ER}}$ neurons to $87.34 \pm 9.12$ A.F.U. in the Gde $2^{\mathrm{lox} /-} ;$ ROSA:Cre ${ }^{\mathrm{ER}}$ mouse (Fig. 9f). Similarly, the average number of lipofuscin granules per neuron increases from $2.75 \pm 0.56$ in Gde2 ${ }^{+/-} ;$ROSA:Cre ${ }^{\text {ER }}$ mice to $9.62 \pm 1.18$ in Gde2 $2^{\text {lox/- }} ; R O S A: C-$ $\mathrm{re}^{\mathrm{ER}}$ animals (Fig. 9g-i). The conditional ablation of Gde2 in the postnatal animal also reproduces the aberrant microglial morphology seen in the constitutive $\mathrm{KO}$ at 6 weeks. Gde $2^{\text {lox/- }} ;$ ROSA:Cre ${ }^{\mathrm{ER}}$ microglia have swollen soma and less elaborate arborizations (Fig. 9j-q). Gde $2^{\text {lox/- }}$ ;ROSA:Cre ${ }^{\mathrm{ER}}$ also exhibit satellitosis of neurons within the ventral horn (Fig. 9r-u). Taken together, these data indicate GDE2's function in preventing neurodegeneration is distinct from its role in regulating motor neuron differentiation.

Release of GPI-anchored GDE2 substrates is impaired in the SOD $1^{\mathrm{G} 93 \mathrm{~A}}$ mouse model of ALS

Our findings indicated that postnatal GDE2 function is critical to prevent degeneration, and raise the possibility that impaired GPI-anchor cleavage mediates neurodegeneration. To discover GPI-anchored proteins regulated by GDE2, we conducted an unbiased proteomic screen using alpha-toxin from Clostridium septicum which specifically binds to GPI-anchors [23]. We prepared non-membrane CNS extracts from aged WT and Gde2 $\mathrm{KO}$ mice and used alpha-toxin to pull down GPI-anchored proteins that were released from the membrane. Protein complexes that yielded more signal in the WT, indicative of impaired GPI-anchor cleavage in the Gde2 $\mathrm{KO}$, were then identified using mass spectrometry. This screen identified two members of the Glypican family of heparin sulfate proteoglycans, Glypican 6 and Glypican 4, and both of these GPIanchored proteins have been reported as substrates of 

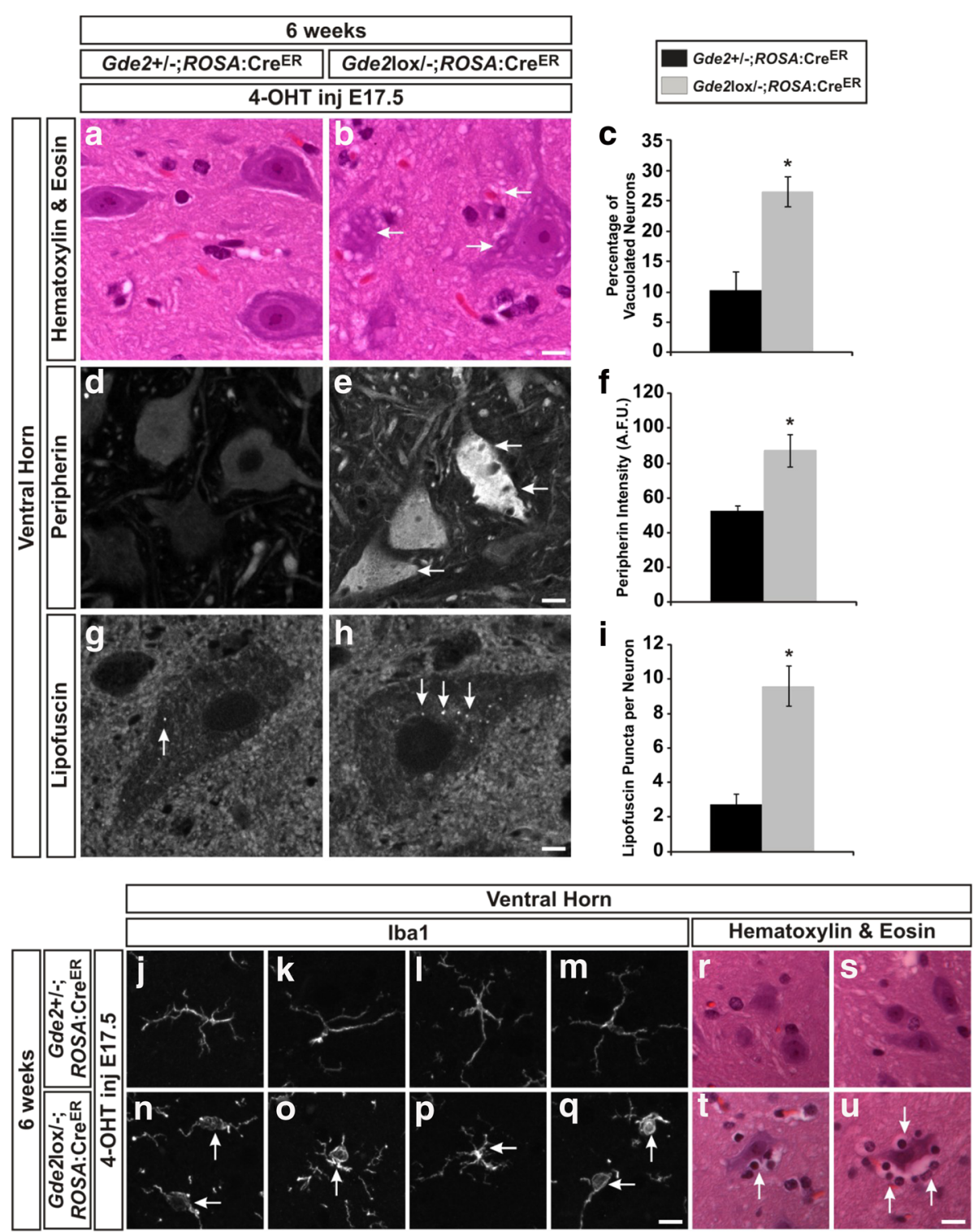

Fig. 9 Gde2 is required postnatally to prevent neurodegeneration. $\mathbf{a}, \mathbf{b}$ H\&E staining shows increased vacuolization in Gde ${ }^{\text {lox/ }} ;$ ROSA:Cre ${ }^{\mathrm{ER}}$ motor neurons (arrows). Scale bar $=10 \mu \mathrm{m}$. c Quantification of increased vacuolization in Gde2 ${ }^{\text {lox- }} ;$ ROSA:Cre ${ }^{\mathrm{ER}}$ mice. ${ }^{*} p=0.007, n=3$. d, e Peripherin

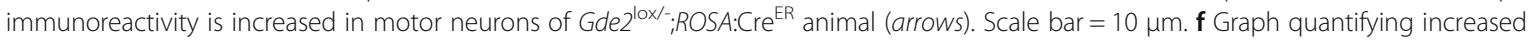
peripherin signal in artificial fluorescence units (A.F.U). ${ }^{*} p=0.011, n=3 . \mathbf{g}, \mathbf{h}$ Enhanced lipofuscin accumulation is seen with the postnatal ablation of Gde2 (arrows). Scale bar $=5 \mu \mathrm{m}$. i Quantification of lipofuscin granules per neuron. ${ }^{*} p=0.002, n=3$. Graphs represent mean \pm SEM, Student's $t$ test. j-q Conditional ablation of Gde2 induces aberrant microglial morphology (arrows), visualized by lba1 staining. Scale bar $=10 \mu \mathrm{m}$. $\mathbf{r}-\mathbf{u}$ Gde2 $^{\text {lox } / \text {; }}$ ROSA:Cre ${ }^{\mathrm{ER}}$ exhibit satellitosis (arrows) comparable to the constitutive Gde2 KO. Scale bar $=20 \mu \mathrm{m}$. See also Additional file 1: Figure S2

GDE2 $[9,13]$. We hypothesized that if the production of non-membrane bound Glypican 4 and Glypican 6 via GPI-anchor cleavage was crucial to prevent degeneration, we should see diminished production of these proteins in mouse models that exhibit motor neuron degeneration. The $S O D 1^{\mathrm{G} 93 \mathrm{~A}}$ transgenic mouse models familial ALS and shows profound motor neuron degeneration [51]. Although less severe, degeneration in Gde2 nulls has considerable phenotypic overlap with the $S O D 1^{\mathrm{G} 93 \mathrm{~A}}$ model, namely vacuolization, neurofilament inclusions, gliosis, and motor neuron death $[52,53]$.

We aged $S O D 1^{\mathrm{G} 93 \mathrm{~A}}$ mice and their non-transgenic littermates (WT) to four months, an age with marked neurodegeneration, and separated protein samples from lumbar spinal cord extracts on the basis of hydrophobicity using sequential solubilization. We first produced an S1 fraction by solubilizing hydrophilic proteins in Tris buffer, and next an S2 fraction via solubilization of hydrophobic 
proteins in a buffer containing $60 \mathrm{mM}$ Octyl $\beta$-Dglucopyranoside [54] (Fig. 10a). We confirmed the effective enrichment of non-membrane protein in the S1 fraction and membrane protein in S2 by performing western blots which show that GAPDH, a hydrophilic cytosolic protein, separates into $\mathrm{S} 1$, and $\mathrm{Na} / \mathrm{K}$ ATPase a hydrophobic transmembrane protein separated into S2 (Fig. 10b). Since impaired membrane release of a GPI-anchored protein would reduce S1 levels, we compared Glypican 6 and Glypican 4 amounts in WT and $S O D 1^{\mathrm{G} 93 \mathrm{~A}} \mathrm{~S} 1$ fractions. We observe that $S O D 1^{\mathrm{G} 93 \mathrm{~A}}$ mice have reduced levels of Glypican 6 and Glypican 4 to $52.98 \pm 14.87 \%$ and $38.82 \pm$ $18.68 \%$ of control mice, respectively (Fig. 10c and d). In addition, we examined Glypican 1, a family member that has been connected with neurodegeneration in the context of Niemann-Pick Disease [17]. Similarly, we find that S1 Glypican 1 levels in the $S O D 1^{\text {G93A }}$ spinal cord are reduced to $39.77 \pm 10.73 \%$ of control littermates (Fig. 10c and $\mathrm{d}$ ). These results indicate that the release of GPIanchored Glypican 6, 4 and 1 is abated in the degenerating $S O D 1^{\mathrm{G} 93 \mathrm{~A}}$ mouse.

\section{Discussion}

This report identifies a novel function for GDE2 in neuronal survival in the adult nervous system that is distinct from its function in embryogenesis. As early as 6 weeks, Gde2 null animals exhibit pathologies analogous to human neurodegeneration including: intracellular vacuolization, microgliosis, accrual of cytoskeletal protein and deposition of lipofuscin. Later in life, Gde2 KO animals show progressive reductions in motor neuron numbers, astrogliosis, and the appearance of spongiform vacuoles. Loss of motor neurons elicits peripheral sprouting evident by increases in motor unit size, culminating in a

\section{Sequential Solubilization}

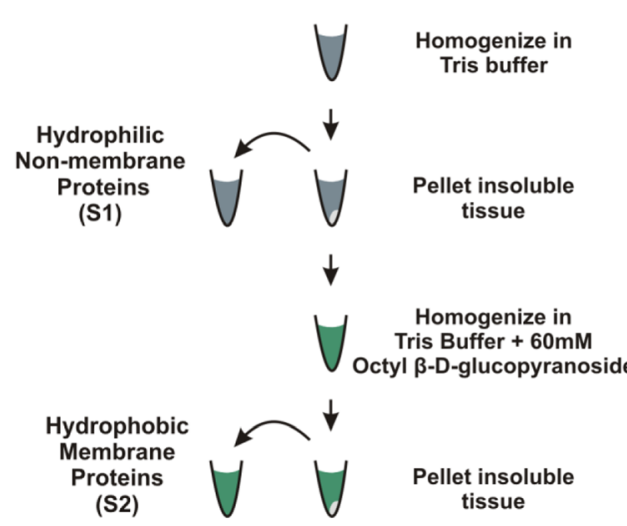

b

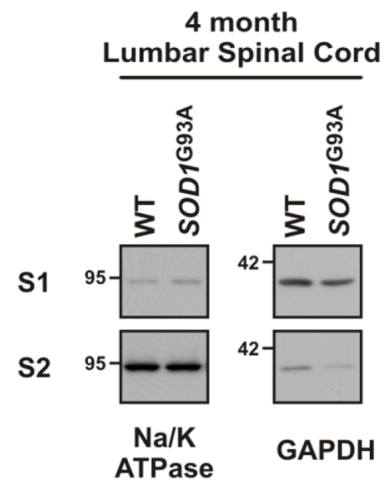

C

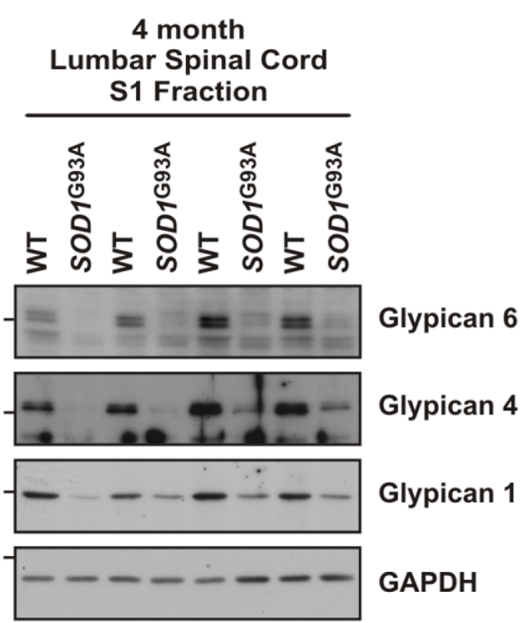

d

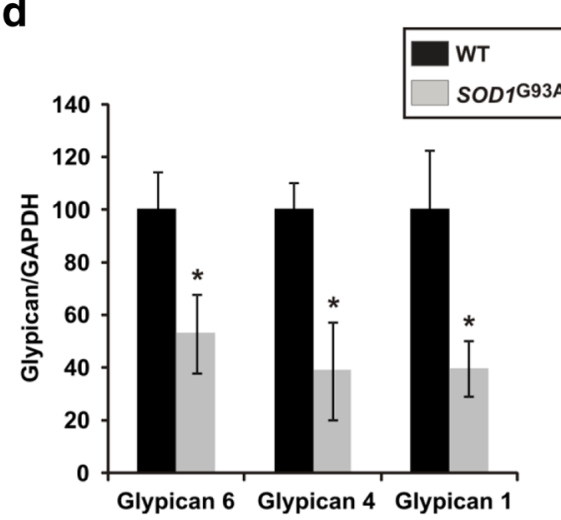

Fig. 10 GDE2 substrates show impaired release in $S O D 1^{G 93 A}$ mice. a Schematic of the sequential solubilization protocol used to separate hydrophilic non-membrane proteins (S1) from hydrophobic membrane proteins (S2). b Western blot demonstrating the successful enrichment of non-membrane protein (GAPDH) in the S1 fraction and membrane protein ( $\mathrm{Na} / \mathrm{K}$ ATPase) in the S2 fraction for WT and SOD $1^{\mathrm{G} 93 \mathrm{~A}}$ transgenic mice. c Western blots visualizing the impaired production of non-membrane bound (S1) Glypican 6, Glypican 4, and Glypican 1 in the lumbar spinal cord of 4 month SOD ${ }^{\mathrm{G} 93 \mathrm{~A}}$ mice. d Quantification of the reduced membrane release of Glypican 6, ${ }^{*} p=0.038$; Glypican 4, ${ }^{*} p=0.016$; and Glypican $1,{ }^{*} p=0.030$ relative to GAPDH. Graph represents mean \pm SEM. Student's $t$ test, $n=4$ WT, 4 SOD $1^{\text {G93A }}$ 
deficits in motor behavior. Further, we show decreased membrane release of GPI-anchored GDE2 substrates belonging to the Glypican family in the $S O D 1^{\mathrm{G} 93 \mathrm{~A}}$ mouse model of familial ALS, suggesting that impaired GPIanchor cleavage may mediate aspects of motor neuron degeneration.

\section{Postnatal versus embryonic functions of GDE2}

GDE2 is expressed in spinal motor neurons during embryonic development and induces neighboring progenitors to differentiate into postmitotic motor neurons $[6,8]$. We find that adult Gde2 $\mathrm{KO}$ animals exhibit progressive spinal motor neuron degeneration. Though our analysis has focused on the lumbar spinal cord, comparable pathology is evident at cervical and thoracic levels. Gde2 $\mathrm{KO}$ animals show an erosion of motor function over time, consistent with the age-dependent degeneration and loss of motor neurons in these animals. Our data argue against the possibility that loss of GDE2 during embryogenesis is responsible for the neurodegeneration observed in adult $G d e 2^{-/-}$animals. During neurogenesis, Gde2 ablation disrupts the generation of late born alpha motor neurons within the LMC that innervate limb musculature; however, no changes are seen in MMC motor neurons which innervate axial muscles nor gamma motor neurons which regulate muscle stretch [8]. In contrast, cell loss in the adult Gde2 $\mathrm{KO}$ encompasses alpha and gamma LMC neurons by 6 months and MMC neurons by 13 months. Thus, motor neuron degeneration in the adult Gde2 KO involves motor neuron subtypes that are not dependent on GDE2 for their initial generation. In addition, selective ablation of GDE2 using an inducible $\mathrm{Cre}^{\mathrm{ER}}$ system after motor neuron differentiation is complete still elicits neurodegenerative pathology. These collective observations suggest that GDE2 function in neuronal survival is distinct from its earlier role in controlling neurogenesis and is attributable to postnatal GDE2 expression in the nervous system. We note that GDE2 is also expressed in layer V cortical neurons [10]; it will be interesting to determine whether these neurons degenerate in the absence of GDE2 and if they also contribute to the motor deficiencies of Gde2 KO animals.

Published profiling studies combined with our in-situ hybridization analyses show that postnatal GDE2 expression is not confined to neurons [27, 28]. While a cell-autonomous role for GDE2 in neurons is feasible, there is a growing body of literature implicating glia in neurodegeneration. Astrocytes, oligodendrocytes, and microglia have been identified as active components in the degeneration of neurons seen in mouse models of Amyotrophic Lateral Sclerosis (ALS) [55, 56] and Alzheimer's Disease [57]. Moving forward it will be important to define the requisite cellular source of GDE2 for neuronal survival.

\section{GDE2 acts centrally to mediate neuronal survival}

Neurodegeneration can initiate within the CNS or begin in the periphery and progress in a retrograde fashion towards cell bodies in the CNS, a process known as Wallerian-like degeneration [58]. Our study suggests that the degenerative pathology observed in Gde2 KOs is not a consequence of Wallerian-like degeneration but is likely to initiate within the CNS itself. Analysis of quadriceps muscles in the Gde2 $\mathrm{KO}$ does not reveal evidence of irregular neuromuscular junction (NMJ) morphology or denervated terminals at 19 months, a time when degenerative pathology is evident within neuronal cell bodies (Additional file 1: Figure S3). Moreover, we did not observe deficits in peripheral conduction times or action potential amplitude, indicating that peripheral axons, Schwann cells, and NMJs are relatively healthy. Further, mice lacking Gde2 take longer to respond in a heat sensitization assay, a behavior that requires functional central and peripheral components. While this test cannot pinpoint which element of the sensorimotor reflex produces the latency, normal motor performance at 6 months and the integrity of peripheral nerve conduction suggest a defect in the central integration of the nociceptive signal rather than peripheral dysfunction. Taken together, these data imply that GDE2 functions centrally to maintain neuronal health and viability.

\section{Pathways regulated by GDE2 activity}

Our developmental studies of GDE2 function identify GDE2 as a transmembrane enzyme that utilizes its extracellular enzymatic domain to cleave GPI-anchors that tether proteins to the membrane. Importantly, GDE2 and its family members GDE3 and GDE6 are the only known GPI-anchor cleaving enzymes in vertebrates that function at the cell surface, and accordingly, are key regulators of GPI-anchored protein activity at the plasma membrane [9]. This implies that GDE2 enzymatic regulation of specific GPI-anchored proteins is central to its function in neuronal survival. We conducted a proteomic screen to identify GPI-anchored substrates of GDE2 and found Glypican 4 and 6, both of which have been reported as GDE2 substrates $[9,13]$. We then demonstrated that the nonmembrane versions of these proteins, as well as Glypican 1 , are reduced in $S O D 1^{\mathrm{G} 93 \mathrm{~A}}$ mice. These results support the hypothesis that the proper regulation of GPI-anchored proteins is crucial for neuronal survival. Moreover, they highlight Glypicans as potential components of pathways essential for neuronal viability whose dysfunction could lead to neurodegeneration. Investigating the role of GPIanchored GDE substrates including Glypicans will be of 
major interest as we continue to define the molecular basis of neurodegeneration in Gde2 $\mathrm{KO}$ animals as well as other models of degeneration.

How GDE2 mediates neuronal survival is a major outstanding question. Clues to the intracellular processes involved can be gleaned from the early degenerative phenotypes. Gde2 KOs accumulate lipofuscin that is often associated or adjacent to $\mathrm{Lamp}^{+}$or CathepsinD ${ }^{+}$lysosomes. Lipofuscin is a complex mixture of oxidized protein, lipid degradation products, carbohydrates, and metals that is deposited during aging; however, the striking appearance of lipofuscin in Gde2 null animals at 6 weeks is in line with a diseased neurodegenerative state rather than normal aging. Lipofuscin accumulation taxes lysosomal function and continually strains cellular clearance, [38] which can produce dire consequences for neuronal function and survival. Impaired cellular clearance may also generate the excess cytoskeletal protein in the Gde2 KO. Disruptions in the cytoskeleton will impair intercellular membrane trafficking, potentially causing vacuolization. As this process begins to mount, first microglia and subsequently astrocytes become activated in response to neuronal stress, and as neurons die they are phagocytosed during satellitosis. Importantly, this model is compatible with the extended, progressive degeneration seen in the Gde2 $\mathrm{KO}$ as chronic burdens on cellular clearance can slowly deteriorate neuronal health over time [38]. Future experiments will address the precise interrelation of the early Gde2 null pathology to better understand which subcellular processes instigate the degeneration.

\section{GDE2 and disease}

This report shows GDE2, a GPI-anchor cleaving enzyme previously identified as necessary for embryonic neuronal differentiation, is a novel survival factor for motor neurons in the postnatal spinal cord, and provides new insight into the fundamental mechanisms governing neuronal survival. Could GDE2 hypofunctionality be an unrecognized component in human disease? Although Gde2 is expressed in humans [59], no disease pedigrees have been linked with mutations in Gde2. However, GDE2 could be functionally inhibited in disease conditions, producing pathology without registering mutations at the genomic level. GDE2 activity is highly sensitive to cellular redox states. High oxidative conditions in the endoplasmic reticulum oxidize cysteine residues within the GDE2 enzymatic domain and prevent GDE2 trafficking to the cell surface [60]. In addition, GDE2 activity at the cell surface can be inhibited by oxidation of cysteine residues within the intracellular $\mathrm{N}$ - and $\mathrm{C}$-termini [7]. We speculate that increased ROS levels in disease conditions could lead to thiol-redox dependent inhibition of GDE2 trafficking and/ or activity that would impinge on its function in neuronal survival. Importantly, elevation of reactive oxygen species (ROS) and oxidative stress are prevalent in many neurodegenerative diseases [61-64], broadening the potential for GDE2 inhibition in disease.

Gde2 was recently identified in a network analysis that generated a broad "HSPome" of potential targets of Hereditary Spastic Paraplegia [65]. Interestingly, the slow rate of motor neuron degeneration in Gde2 KOs is similar to HSP and certain forms of Spinal Muscular Atrophy [66, 67]. In addition, decreased expression of Gde2 has been observed in laser captured motor neurons from sporadic ALS patients [68]. These observations reinforce the compelling notion that GDE2 dysfunction may underlie aspects of human neurodegenerative disease. Moving forward, verifying GDE2 hypofunctionality in human disease will be of paramount importance, and elucidating the mechanisms by which GDE2 regulates neuronal survival will be crucial to develop strategies to mitigate neurodegeneration.

\section{Conclusion}

This report identifies GDE2 as a novel survival factor for spinal neurons in the adult nervous system. Gde2 knock-out animals exhibit a progressive neurodegeneration marked by pathologies mirroring human disease. Conditional ablation of Gde2 demonstrates that GDE2 functions postnatally to ensure neuronal health and survival. In addition, we find that the production of membrane released Glypicans, GPI-anchored substrates of GDE2, is reduced in the $S O D 1^{\mathrm{G} 93 \mathrm{~A}}$ mouse model. Our findings implicate diminished GDE2 function as a novel component in the etiology of several diverse neurodegenerative pathologies, and raise the possibility that improper regulation of GPI-anchored GDE2 substrates is mechanistically linked to neurodegeneration.

\section{Additional files}

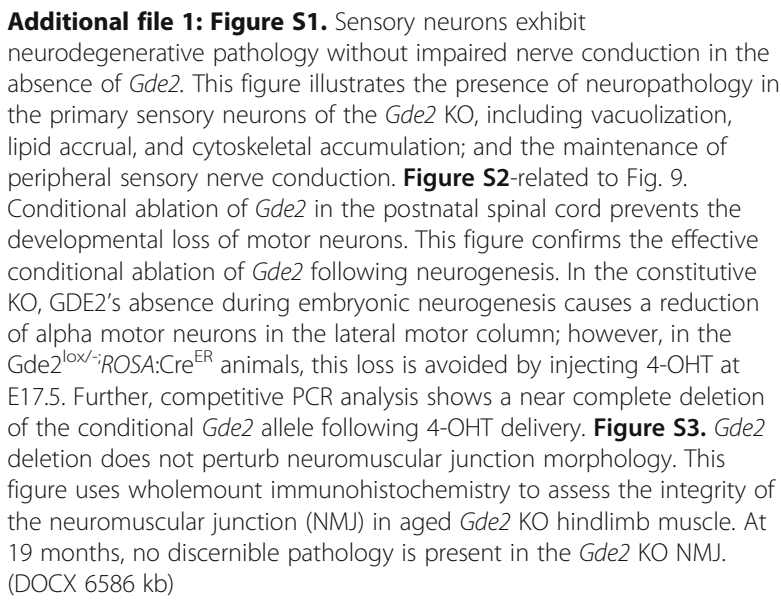




\section{Abbreviations}

4-OHT: 4-Hydroxytamoxifen; AD: Alzheimer's Disease; AFU: Artificial fluorescence units; ALS: Amyotrophic Lateral Sclerosis; ChAT: Choline Acetyltransferase; CMAP: Compound Motor Action Potential; DRG: Dorsal Root Ganglion; FISH: Fluorescent in-situ hybridization; GDE2: Glycerophosphodiester phosphodiesterase 2;

GDPD: Glycerophosphodiester phosphodiesterase;

GPI: Glycosylphosphatidylinositol; H\&E: Hematoxylin and Eosin; KO: Knock out; LMC: Lateral motor column; MMC: Medial motor column; MN: Motor neuron; MNCS: Motor Nerve Conduction Study; MUNE: Motor Unit Number Estimation; NF-H: Neurofilamant-H; NMJ: Neuromuscular junction; RECK: REversion-inducing Cysteine-rich protein with Kazal motifs; ROS: Reactive oxygen species; SNAP: Sensory Nerve Action Potential; WT: Wild type

\section{Acknowledgements}

We thank Priyanka Sabharwal and Annie van Beuningen for initial observations: Nicole Reed and Jeremy Shefner for assistance with electrophysiology; Josh Crawford for technical support with behavioral tests; David Huso and the School of Medicine Pathology Core for technical guidance; Michele Pucak and the Neuroscience Multiphoton Core for technical support; and Ross Tomaino and the Harvard Taplin Mass Spectrometry facility for technical support. We thank Jeremy Nathans for contributing the ROSA:Cre ${ }^{\mathrm{ER}}$ line.

\section{Funding}

This work was funded by grants from the Muscular Dystrophy Association, Robert Packard Center for ALS Research, National Institutes of Health RO1NS046336; C.C. was supported by T32EY017203.

\section{Availability of data and materials}

Additional files and the full manuscript are available online.

\section{Authors' contributions}

CC designed experiments, performed histology, western blots, physiology, behavior, data analysis and wrote the manuscript. SP designed and carried out the alpha toxin assay and performed western blots. MN assisted with the alpha toxin assay and western blots. MR generated the Gde $2^{\text {lox/ }}:$ ROSA:Cre ${ }^{E R}$ mice. AH designed the electrophysiology experiments and performed data analysis. MP designed behavior experiments and performed data analysis. SS designed experiments, performed data analysis, and wrote the manuscript. All authors read and approved the final manuscript.

\section{Authors' information}

Not applicable.

\section{Competing interests}

The authors declare that they have no competing interests.

\section{Consent for publication}

Not Applicable.

\section{Ethics approval}

Animals were maintained and used in accordance with approved Johns Hopkins University Institutional Animal Care and Use Committee (IACUC) protocols. The consent of human subjects is not applicable.

\section{Author details \\ ${ }^{1}$ The Solomon H. Snyder Department of Neuroscience, Johns Hopkins University School of Medicine, 725 N Wolfe Street, PCTB 1004, Baltimore, MD 21205, USA. ${ }^{2}$ Department of Neurology, Johns Hopkins University School of Medicine, Baltimore, USA. ${ }^{3}$ Department of Psychiatry, Johns Hopkins University School of Medicine, Baltimore, USA. ${ }^{4}$ University of Utah, BPRB 390D South 2030 East, Salt Lake City, UT 84112, USA. ${ }^{5}$ Bascom Palmer Eye Institute, 900 NW 17th St, Miami, FL 33136, USA.}

Received: 20 July 2016 Accepted: 5 January 2017 Published online: 19 January 2017

\section{References}

1. Gould E. How widespread is adult neurogenesis in mammals? Nat Rev Neurosci. 2007;8:481-8.
2. Bjornsson CS, Apostolopoulou M, Tian Y, Temple S. It takes a village: constructing the neurogenic niche. Dev Cell. 2015:32:435-46.

3. Corda D, Mosca MG, Ohshima N, Grauso L, Yanaka N, Mariggiò S. The emerging physiological roles of the glycerophosphodiesterase family. FEBS J. 2014:281:998-1016.

4. Yanaka N. Mammalian glycerophosphodiester phosphodiesterases. Biosci Biotechnol Biochem. 2007;71:1811-8.

5. Corda D, Kudo T, Zizza P, lurisci C, Kawai E, Kato N, Yanaka N, Mariggiò S. The developmentally regulated osteoblast phosphodiesterase GDE3 is glycerophosphoinositol-specific and modulates cell growth. J Biol Chem. 2009:284:24848-56

6. Rao M, Sockanathan S. Transmembrane protein GDE2 induces motor neuron differentiation in vivo. Science. 2005:309:2212-5.

7. Yan Y, Sabharwal P, Rao M, Sockanathan S. The antioxidant enzyme Prdx1 controls neuronal differentiation by thiol-redox-dependent activation of GDE2. Cell. 2009;138:1209-21.

8. Sabharwal P, Lee C, Park S, Rao M, Sockanathan S. GDE2 regulates subtypespecific motor neuron generation through inhibition of Notch signaling. Neuron. 2011;71:1058-70.

9. Park S, Lee C, Sabharwal P, Zhang M, Meyers CLF, Sockanathan S. GDE2 Promotes Neurogenesis by Glycosylphosphatidylinositol-Anchor Cleavage of RECK. Science. 2013;339:324-8.

10. Rodriguez M, Choi J, Park S, Sockanathan S. Gde2 regulates cortical neuronal identity by controlling the timing of cortical progenitor differentiation. Development. 2012;139:3870-9.

11. Chatterjee S, Mayor S. The GPI-anchor and protein sorting. Cell Mol Life Sci. 2001;58:1969-87.

12. The UniProt Consortium. UniProt: a hub for protein information. Nucleic Acids Res. 2014;43:D204-212

13. Matas-Rico E, van Veen M, Leyton-Puig D, van den Berg J, Koster J, Kedziora KM, Molenaar B, Weerts MJA, de Rink I, Medema RH, Giepmans BNG, Perrakis A, Jalink K, Versteeg R, Moolenaar WH. Glycerophosphodiesterase GDE2 promotes neuroblastoma differentiation through glypican release and is a marker of clinical outcome. Cancer Cell. 2016:30:548-62.

14. Radford HE, Mallucci GR. The role of GPI-anchored PrP C in mediating the neurotoxic effect of scrapie prions in neurons. Curr Issues Mol Biol. 2010;12:119-27

15. Yang LB, Li R, Meri S, Rogers J, Shen Y. Deficiency of complement defense protein CD59 may contribute to neurodegeneration in Alzheimer's disease. J Neurosci. 2000;20:7505-9.

16. Watanabe N. Glypican-1 as an A binding HSPG in the human brain: Its localization in DIG domains and possible roles in the pathogenesis of Alzheimer's disease. FASEB J. 2004;18(9):1013-5.

17. Mani K, Cheng F, Fransson L-A. Defective nitric oxide-dependent, deaminative cleavage of glypican-1 heparan sulfate in Niemann-Pick C1 fibroblasts. Glycobiology. 2006;16:711-8.

18. Glas M, Popp B, Angele B, Koedel U, Chahli C, Schmalix WA, Anneser JM, Pfister HW, Lorenzl S. A role for the urokinase-type plasminogen activator system in amyotrophic lateral sclerosis. Exp Neurol. 2007;207:350-6

19. Lagier-Tourenne C, Polymenidou M, Hutt KR, Vu AQ, Baughn M, Huelga SC, Clutario KM, Ling S-C, Liang TY, Mazur C, Wancewicz E, Kim AS, Watt A, Freier S, Hicks GG, Donohue JP. Shiue L, Bennett CF, Ravits J, Cleveland DW, Yeo GW. Divergent roles of ALS-linked proteins FUS/TLS and TDP-43 intersect in processing long pre-mRNAs. Nat Neurosci. 2012;15:1488-97.

20. Wong PC, Cai H, Borchelt DR, Price DL. Genetically engineered mouse models of neurodegenerative diseases. Nat Neurosci. 2002;5:633-9.

21. Rothstein JD. Current hypotheses for the underlying biology of amyotrophic lateral sclerosis. Ann Neurol. 2009;65 Suppl 1:\$3-9.

22. Schaeren-Wiemers N, Gerfin-Moser A. A single protocol to detect transcripts of various types and expression levels in neural tissue and cultured cells: in situ hybridization using digoxigenin-labelled cRNA probes. Histochemistry. 1993;100:431-40.

23. Zhao P, Nairn AV, Hester S, Moremen KW, O'Regan RM, Oprea G, Wells L, Pierce M, Abbott KL. Proteomic identification of glycosylphosphatidylinosito anchor-dependent membrane proteins elevated in breast carcinoma. J Biol Chem. 2012;287:25230-40

24. Shevchenko A, Wilm M, Vorm O, Mann M. Mass spectrometric sequencing of proteins silver-stained polyacrylamide gels. Anal Chem. 1996;68:850-8.

25. Peng J, Gygi SP. Proteomics: the move to mixtures. J Mass Spectrom. 2001; 36:1083-91. 
26. Eng JK, McCormack AL, Yates JR. An approach to correlate tandem mass spectral data of peptides with amino acid sequences in a protein database. J Am Soc Mass Spectrom. 1994;5:976-89.

27. Cahoy JD, Emery B, Kaushal A, Foo LC, Zamanian JL, Christopherson KS, Xing Y, Lubischer JL, Krieg PA, Krupenko SA, Thompson WJ, Barres BA. A transcriptome database for astrocytes, neurons, and oligodendrocytes: a new resource for understanding brain development and function. J Neurosci. 2008;28:264-78.

28. Zhang Y, Chen K, Sloan SA, Bennett ML, Scholze AR, O'Keeffe S, Phatnan HP, Guarnieri P, Caneda C, Ruderisch N, Deng S, Liddelow SA, Zhang C, Daneman R, Maniatis T, Barres BA, Wu JQ. An RNA-sequencing transcriptome and splicing database of glia, neurons, and vascular cells of the cerebral cortex. J Neurosci. 2014;34:11929-47.

29. Garman RH. Histology of the central nervous system. Toxicol Pathol. 2011;39:22-35

30. Kreutzberg GW. Microglia: a sensor for pathological events in the CNS Trends Neurosci. 1996;19:312-8.

31. Barres BA. The mystery and magic of glia: a perspective on their roles in health and disease. Neuron. 2008;60:430-40.

32. Xiao S, McLean J, Robertson J. Neuronal intermediate filaments and ALS: a new look at an old question. Biochim Biophys Acta. 2006;1762:1001-12.

33. Gray E, Rice C, Nightingale H, Ginty M, Hares K, Kemp K, Cohen N, Love S, Scolding N, Wilkins A. Accumulation of cortical hyperphosphorylated neurofilaments as a marker of neurodegeneration in multiple sclerosis. Mult Scler. 2013;19:153-61.

34. Lalonde R, Strazielle C. Neurobehavioral characteristics of mice with modified intermediate filament genes. Rev Neurosci. 2003;14:369-85.

35. Bruijn LI, Miller TM, Cleveland DW. Unraveling the mechanisms involved in motor neuron degeneration in ALS. Annu Rev Neurosci. 2004;27:723-49.

36. Schnell SA, Staines WA, Wessendorf MW. Reduction of lipofuscin-like autofluorescence in fluorescently labeled tissue. J Histochem Cytochem. 1999:47:719-30.

37. Frank A, Christensen A. Localization of acid phosphatase in lipofuscin granules and possible autophagic vacuoles in interstitial cells of the guinea pig testis. J Cell Biol. 1968;36:1-13.

38. Gray DA, Woulfe J. Lipofuscin and aging: a matter of toxic waste. Sci Aging Knowl Environ. 2005. doi:10.1126/sageke.2005.5.re1.

39. Mink JW, Augustine EF, Adams HR, Marshall FJ, Kwon JM. Classification and natural history of the neuronal ceroid lipofuscinoses. J Child Neurol. 2013;28: $1101-5$.

40. Kanning KC, Kaplan A, Henderson CE. Motor neuron diversity in development and disease. Annu Rev Neurosci. 2010;33:409-40.

41. Friese A, Kaltschmidt JA, Ladle DR, Sigrist M, Jessell TM, Arber S. Gamma and alpha motor neurons distinguished by expression of transcription factor Err3. Proc Natl Acad Sci. 2009;106:13588-93.

42. Keswani SC, Jack C, Zhou C, Höke A. Establishment of a rodent model of HIV-associated sensory neuropathy. J Neurosci. 2006;26:10299-304.

43. Shefner JM, Cudkowicz M, Brown RH. Motor unit number estimation predicts disease onset and survival in a transgenic mouse model of amyotrophic lateral sclerosis. Muscle Nerve. 2006;34:603-7.

44. Shefner JM. Recent MUNE studies in animal models of motor neuron disease. Suppl Clin Neurophysiol. 2009;60:203-8.

45. Daube JR. Motor unit number estimates-from A to Z. J Neurol Sci. 2006;242: 23-35.

46. Filali M, Lalonde R, Rivest $\mathrm{S}$. Sensorimotor and cognitive functions in a SOD1(G37R) transgenic mouse model of amyotrophic lateral sclerosis. Behav Brain Res. 2011;225:215-21.

47. Brooks SP, Dunnett SB. Tests to assess motor phenotype in mice: a user's guide. Nat Rev Neurosci. 2009;10:519-29.

48. Le Bars D, Gozariu M, Cadden SW. Animal models of nociception. Pharmacol Rev. 2001;53:597-652.

49. Badea TC, Wang Y, Nathans J. A noninvasive genetic/pharmacologic strategy for visualizing cell morphology and clonal relationships in the mouse. J Neurosci. 2003:23:2314-22.

50. Kim K, Jarry H, Knoke I, Seong JY, Leonhardt S, Wuttke W. Competitive PCR for quantitation of gonadotropin-releasing hormone mRNA level in a single micropunch of the rat preoptic area. Mol Cell Endocrinol. 1993;97:153-8.

51. Gurney ME, Pu H, Chiu AY, Dal Canto MC, Polchow CY, Alexander DD, Caliendo J, Hentati A, Kwon YW, Deng HX. Motor neuron degeneration in mice that express a human $\mathrm{Cu}, \mathrm{Zn}$ superoxide dismutase mutation. Science. 1994;264:1772-5
52. Vinsant S, Mansfield C, Jimenez-Moreno R, Moore VDG, Yoshikawa M, Hampton TG, Prevette D, Caress J, Oppenheim RW, Milligan C. Characterization of early pathogenesis in the SOD1G93A mouse model of ALS: Part II, results and discussion. Brain Behav. 2013:3:431-57.

53. Vinsant S, Mansfield C, Jimenez-Moreno R, Del Gaizo Moore V, Yoshikawa M, Hampton TG, Prevette D, Caress J, Oppenheim RW, Milligan C. Characterization of early pathogenesis in the SOD1(G93A) mouse model of ALS: part I, background and methods. Brain Behav. 2013;3:335-50.

54. Hooper NM, Turner AJ. Ectoenzymes of the kidney microvillar membrane. Differential solubilization by detergents can predict a glycosylphosphatidylinositol membrane anchor. Biochem J. 1988;250:865-9.

55. Yamanaka K, Chun SJ, Boillee S, Fujimori-Tonou N, Yamashita H, Gutmann DH, Takahashi R, Misawa H, Cleveland DW. Astrocytes as determinants of disease progression in inherited amyotrophic lateral sclerosis. Nat Neurosci. 2008;11:251-3.

56. Lee $Y$, Morrison BM, Li Y, Lengacher S, Farah MH, Hoffman PN, Liu Y, Tsingalia A, Jin L, Zhang P-W, Pellerin L, Magistretti PJ, Rothstein JD. Oligodendroglia metabolically support axons and contribute to neurodegeneration. Nature. 2012;487:443-8.

57. Hong S, Beja-Glasser VF, Nfonoyim BM, Frouin A, Li S, Ramakrishnan S, Merry KM, Shi Q, Rosenthal A, Barres BA, Lemere CA, Selkoe DJ, Stevens B. Complement and microglia mediate early synapse loss in Alzheimer mouse models. Science. 2016;352:712-6.

58. Chaudhry V, Glass JD, Griffin JW. Wallerian degeneration in peripheral nerve disease. Neurol Clin. 1992;10:613-27.

59. Uhlén M, Fagerberg L, Hallström BM, Lindskog C, Oksvold P, Mardinoglu A, Sivertsson Å, Kampf C, Sjöstedt E, Asplund A, Olsson I, Edlund K, Lundberg E, Navani S, Szigyarto CA-K, Odeberg J, Djureinovic D, Takanen JO, Hober S, Alm T, Edqvist P-H, Berling H, Tegel H, Mulder J, Rockberg J, Nilsson P, Schwenk JM, Hamsten M, von Feilitzen K, Forsberg M, et al. Proteomics. Tissue-based map of the human proteome. Science. 2015. doi:10.1126/science.1260419.

60. Yan Y, Wladyka C, Fujii J, Sockanathan S. Prdx4 is a compartment-specific $\mathrm{H} 2 \mathrm{O} 2$ sensor that regulates neurogenesis by controlling surface expression of GDE2. Nat Commun. 2015;6:7006.

61. Cobb CA, Cole MP. Oxidative and nitrative stress in neurodegeneration. Neurobiol Dis. 2015;84:4-21.

62. Simpson EP, Henry YK, Henkel JS, Smith RG, Appel SH. Increased lipid peroxidation in sera of ALS patients: a potential biomarker of disease burden. Neurology. 2004;62:1758-65.

63. Markesbery WR, Lovell MA. Four-hydroxynonenal, a product of lipid peroxidation, is increased in the brain in Alzheimer's disease. Neurobiol Aging. 1998;19:33-6.

64. Alam ZI, Daniel SE, Lees AJ, Marsden DC, Jenner P, Halliwell B. A generalised increase in protein carbonyls in the brain in Parkinson's but not incidental Lewy body disease. J Neurochem. 1997;69:1326-9.

65. Novarino G, Fenstermaker AG, Zaki MS, Hofree M, Silhavy JL, Heiberg AD, Abdellateef M, Rosti B, Scott E, Mansour L, Masri A, Kayserili H, Al-Aama JY, Abdel-Salam GM, Karminejad A, Kara M, Kara B, Bozorgmehri B, Ben-Omran T, Mojahedi F, Mahmoud IG, Bouslam N, Bouhouche A, Benomar A, Hanein S, Raymond L, Forlani S, Mascaro M, Selim L, Shehata N, et al. Exome sequencing links corticospinal motor neuron disease to common neurodegenerative disorders. Science. 2014;343:506-11.

66. Zanoteli E, Maximino JR, Conti Reed U, Chadi G. Spinal muscular atrophy: from animal model to clinical trial. Funct Neurol. 2010;25:73-9.

67. Fink JK. Hereditary spastic paraplegia: clinical principles and genetic advances. Semin Neurol. 2014;34:293-305.

68. Rabin SJ, Kim JMH, Baughn M, Libby RT, Kim YJ, Fan Y, Libby RT, La Spada A, Stone B, Ravits J. Sporadic ALS has compartment-specific aberrant exon splicing and altered cell-matrix adhesion biology. Hum Mol Genet. 2010;19:313-28. 